\title{
Study on the ultrasonic guided wave and online visual monitoring for ultrasonic precise bonding
}

\section{Yibo Sun ( $\nabla$ yibo_sun@126.com )}

Dalian Jiaotong University

\section{Mengruo Cao}

Dalian Jiaotong University

\section{Li Zou}

Dalian Key Laboratory of Welded Structures and Intelligent Manufacturing Technology of Rail Transportation Equipment

\section{Xinhua Yang}

Dalian Key Laboratory of Welded Structures and Intelligent Manufacturing Technology of Rail Transportation Equipment

\section{Research Article}

Keywords: Ultrasonic bonding, Vibration analysis, Time-frequency characteristics, In-situ visual monitoring, Ultrasonic guided wave

Posted Date: April 8th, 2021

DOl: https://doi.org/10.21203/rs.3.rs-401513/v1

License: (c) (1) This work is licensed under a Creative Commons Attribution 4.0 International License. Read Full License

Version of Record: A version of this preprint was published at The International Journal of Advanced Manufacturing Technology on August 3rd, 2021. See the published version at https://doi.org/10.1007/s00170-021-07799-5. 


\title{
Study on the ultrasonic guided wave and online visual monitoring for ultrasonic precise bonding
}

\author{
Yibo Sun ${ }^{1}$, Mengruo $\mathrm{Cao}^{1}$, Li Zou ${ }^{2}$, Xinhua Yang ${ }^{2}$ \\ ${ }^{1}$ College of Locomotive and Rolling stock Engineering, Dalian Jiaotong University, Dalian, China \\ ${ }^{2}$ Dalian Key Laboratory of Welded Structures and Intelligent Manufacturing Technology of Rail Transportation \\ Equipment, Dalian, China
}

\begin{abstract}
Ultrasonic precise bonding is an emerging technology in the application of polymer micro-assembly. In the ultrasonic bonding process, the propagation of ultrasound varies with the change of the interfacial polymer physical state. So the ultrasonic guided wave is an effective parameter to in-situ monitor the fusion degree. The ultrasonic guided wave in the ultrasonic bonding process is studied by vibration analysis and online visual monitoring in this paper. The time-frequency characteristics in the ultrasonic guided wave in the bonding process are mainly analyzed by Fast Fourier Transform spectrum analysis, Wavelet Packet Decomposition, and envelope spectrum methods. The polymer interfacial fusion is monitored by the high-speed HD camera in the ultrasonic bonding process. The time-frequency characteristics in the ultrasonic guided wave and the fusion behavior of the thermal melt interface are analyzed and correlated. Results indicate that the change of the interfacial thermal melt state is related to the time-frequency characteristics of the ultrasonic guided wave. The fusion of the melting zone, the rotation of the micro-device, the generation or disappearance of local air bubbles all lead to the changing of the harmonic frequency and intensity in the ultrasonic bonding process.
\end{abstract}

Keywords: Ultrasonic bonding; Vibration analysis; Time-frequency characteristics; In-situ visual monitoring; Ultrasonic guided wave

Corresponding author: Yibo Sun, College of Locomotive and Rolling stock Engineering, Dalian Jiaotong University, Dalian, China.

E-mail: yibo_sun@126.com

\section{Introduction}

Since the 1990s, polymer micro-device has been widely used in the manufacture of MEMS devices such as microfluidic biochips, micro fuel cells, micro-valves, and micro-pumps due to high forming efficiency and light weight $[1,2]$. As the improvement of the application technology of micro-devices, the demand for multi-functional integrated polymer micro-devices increased. The precise bonding of polymer micro-devices is the key in micro-nano manufacturing. Several bonding techniques have been applied in micro-nano manufacturing such as thermal bonding [3], laser bonding [4], adhesive bonding [5], microwave bonding [6], and ultrasonic bonding [7]. Compared with other bonding methods, ultrasonic bonding is more efficient. Ultrasonic bonding is suitable for most thermoplastic polymer materials without additional implantation of energy-absorbing media. The complexity of the bonding process is reduced. The heat-affected 
zone is controlled in a small area near the interface by the reasonable interface structure and process parameter configuration. The structural thermal deformation is little.

Ultrasonic bonding technology uses high-frequency periodic mechanical force to move two parts relative to each other and generates heat locally by interface friction and periodic energy loss of materials. Wu et al. [8] studied the interfacial friction heating mechanism through experiments and numerical schemes. The results indicate that the interfacial friction heating of polymer granules is a transient process with an inhomogeneous temperature field around the interface. The interfacial friction heating only acts in the initial stage of the ultrasonic bonding process. The flow rate of interfacial friction heating increases with the increase of ultrasonic amplitude. Zhang et al. [9] measured the interface temperature to study the heating mechanism. Results of simulation and experiment reveal that viscoelastic heat provides the most required heat in the bonding process when the temperature reaches $\mathrm{Tg}$ (glass transition temperature) of the material.

Ultrasonic bonding was first performed in the mid-1960s. Matheny et al. [10] introduced the process principle of ultrasonic metal bonding of softer alloys of copper, aluminum, and nickel, and the advantages and disadvantages of the bonding process. Benatar et al. [11] studied the difference between near and far-field ultrasonic bonding and discussed the weldability of thermoplastic materials. Truckenmuller et al. [12] first applied ultrasonic bonding technology to the bonding and packaging of microfluidic chips and the assembly of micro-pumps, micro-valves, and other small devices, which guided ultrasonic bonding technology in the field of MEMS in 2006. Jingmin Li et al. [13] designed an energy director structure and self-balancing jig to improve the uniformity of the microchannel height and provide an effective method for large-scale ultrasonic bonding of microfluidic devices. For the bonding of metal and polymer materials, Kim Jongbaeg et al. [14] developed a miniature ultrasonic bonding device to realize the bonding of cellulose acetate micro-devices. Zhang et al. [15] verified the effectiveness of a new thermally-assisted ultrasonic bonding method for polymer Micro/NanoElectro-Mechanical Systems (M/NEMS) through bonding experiments on PMMA microfluidic chips. Sun et al. [16] proposed an ultrasonic precise bonding method based on ultrasonic propagation efficiency feedback to effectively improve the precision of ultrasonic bonding.

Online visual monitoring is introduced based on the ultrasonic guided wave feedback. The time-frequency characteristics are extracted by the vibration algorithm based on the time-frequency domain analysis method. The polymer interfacial thermal melt state is monitored and recorded by the high-speed HD camera online. The correlation between the time-frequency characteristics and the thermal melt state is analyzed on the same time scale. Compared with the traditional time, pressure, energy, and other parameter control methods, the monitoring of the thermal melt interface provides an effective method for the ultrasonic guided wave in this study.

This paper is organized as follows. Section 2 introduces experimental materials and the control flow of the test rig. Section 3 introduces the vibration analysis methods. The correlation between the time-frequency characteristics and the thermal melt state change is studied in Section 4. Finally, conclusions are drawn in Section 5.

\section{Polymer ultrasonic precise bonding experiment}


The bonding of connecting tube and substrate is carried out in experiments. PMMA is chosen to be the material for its high transparency, low price, easy processing. PMMA is a thermoplastic material, which is usually used as a substitute for glass. The glass transition temperature of PMMA is approximately $105^{\circ} \mathrm{C}$. The PMMA connecting tube and PMMA substrate are shown in Fig.1. The substrate is a rectangular parallelepiped of $8 \mathrm{~mm} \times 8 \mathrm{~mm} \times 2 \mathrm{~mm}$, and the connecting pipe is a hollow cylinder with an outer diameter of $4 \mathrm{~mm}$, an inner diameter of $1 \mathrm{~mm}$, and a thickness of $2 \mathrm{~mm}$.

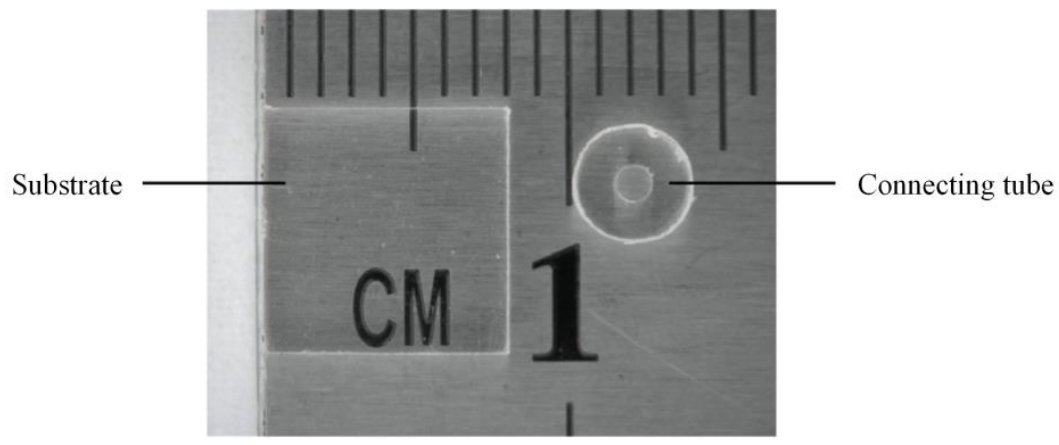

Fig.1. PMMA connecting tube and PMMA substrate

The ultrasonic precise bonding test rig is established to study the correlation between the time-frequency characteristics in the ultrasonic guided wave and the thermal melt state change of the thermal melt interface during the polymer ultrasonic precise bonding process. The ultrasonic precise bonding test rig is shown in Fig.2. The test rig is mainly composed of five parts: an ultrasonic system, a displacement-driven pressurizing mechanism, a leveling mechanism, a sensor detection module, and a high-speed HD camera.

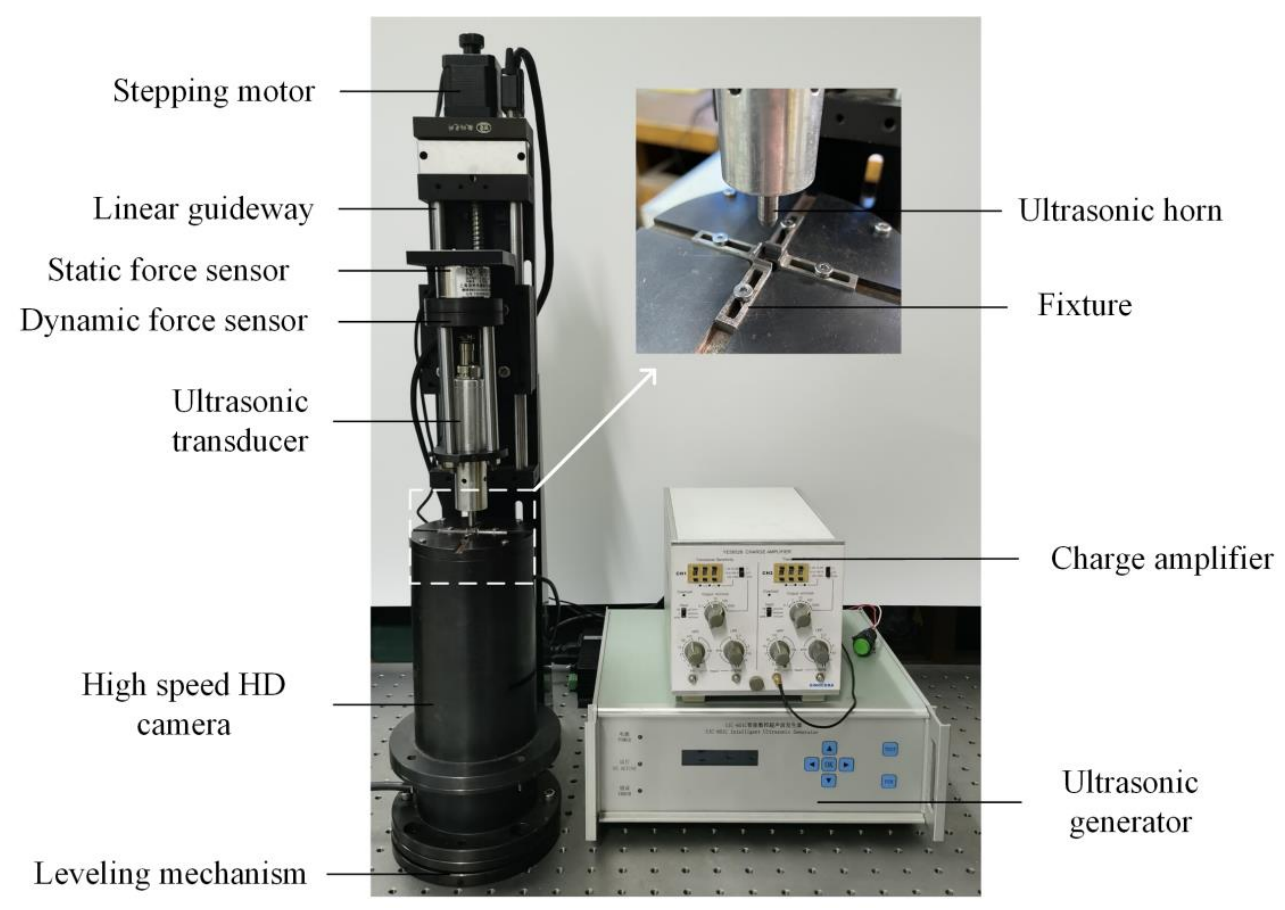

Fig.2. The ultrasonic precise bonding test rig 
The ultrasonic system includes a numerical control ultrasonic generator, a transducer, and an ultrasonic horn. The ultrasound is provided by the numerical control ultrasonic generator, and the ultrasonic frequency is set to be $60 \mathrm{kHz}$. The electrical energy is converted into mechanical energy by the transducer. Mechanical energy is transferred to the PMMA components by the ultrasonic horn. The movement of the ultrasonic horn is driven by the stepping motor and the linear motion guideway, which is a kind of displacement-driven pressure mode. Compared with the pneumatic pressure mode, it is more accurate and stable in the control of the pressure and deformation. The horn is driven to move longitudinally by the pressurizing mechanism to provide pre-tightening force for the micro-device. The sensor detection module includes CL-YD-301 piezoelectric dynamic force sensor produced by United Energy Electronics, EVT-20G static force sensor produced by Shanghai Youran Sensing Technology Co., Ltd., YE5852B type charge amplifier produced by Jiangsu Donghua Co., Ltd., and data acquisition card produced by Advantech Co., Ltd.. Leveling mechanism is designed to ensure that the horn and the bonding interface of the micro-device remain vertical in the experiment.

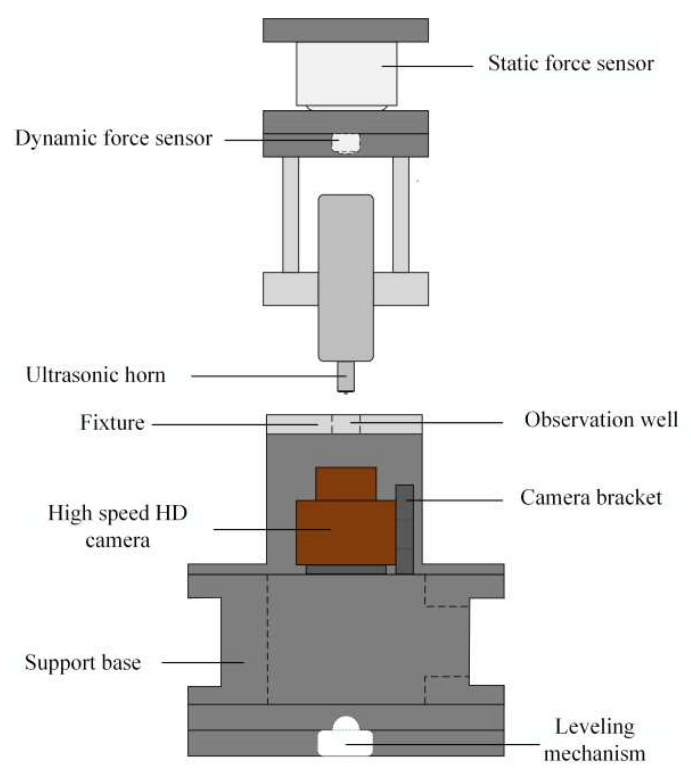

Fig.3. The basic principle diagram of the polymer ultrasonic precise bonding test rig

As shown in Fig.3, the EVT-20G static force sensor produced by Shanghai Youran Sensing Technology Co., Ltd. is installed in the fixture of the ultrasonic horn. The pre-tightening force is measured by the static force sensor and adjusted by the linear motion guideway. In the ultrasonic bonding process, the components are compressed by the horn, and interfacial fusion is achieved under ultrasonic vibration. The vary of interfacial polymer physical state leads to the change of ultrasonic guided waves in the whole structure. The CL-YD-301 dynamic force sensor produced by United Energy Electronics is fixed under the static force sensor to measure the ultrasonic guided wave generated from the horn through the fixture. The high-speed HD camera produced by Shenzhen YVSION Technology Co., Ltd. is installed in the base to observe the interfacial fusion of polymer components.

\section{Vibration analysis algorithm}


The ultrasonic guided wave is analyzed by time domain, frequency domain, and time-frequency domain methods. The applied methods include Fast Fourier Transform $(F F T)$ spectrum analysis, Wavelet Packet Decomposition(WPD), and envelope spectrum respectively.

\subsection{FFT spectrum analysis}

Spectrum analysis is a common frequency domain analysis method. The signal spectrum is the total set of all frequency components that make up the signal. The signal is transformed from the time domain to the frequency domain by $F F T$ to obtain the frequency components of the vibration signal. FFT is an efficient and fast algorithm to deal with big data. For point $N$ sequence $x(n)$, the FFT pair is:

$$
\begin{array}{cc}
X(k)=\sum_{n=0}^{N-1} x(n) W_{N}^{k n} & k=0,1, \cdots, N-1 \\
W_{\mathrm{N}}=\exp \left\{-\mathrm{j} \frac{2 \pi}{\mathrm{N}}\right\} & \\
x(n)=\frac{1}{N} \sum_{k=0}^{N-1} X(k) W_{N}^{-n k} & n=0,1, \cdots, N-1
\end{array}
$$

The computation of $N$ points $X(k)$ requires $N^{2}$ complex multiplication and $N(N-1)$ complex addition. Realizing a complex number multiplication requires 4 real number multiplications and 2 real number additions, realizing a complex number addition requires 2 real number additions. It is found that the amount of calculation is huge.

The characteristics of $F F T$ are as follows:

$$
\begin{gathered}
\text { Periodicity: } W_{N}^{\mathrm{n}(N-K)}=W_{N}^{K(N-n)}=W_{N}^{-n K} \\
\text { Symmetry: } W_{N}^{\mathrm{n}+\mathrm{N} / 2}=-W_{N}^{n},\left(W_{N}^{N-\mathrm{n}}\right)^{*}=W_{N}^{n} \\
\text { Reducibility: } W_{N}^{\mathrm{n} K}=W_{m K}^{m n K}, \quad W_{N}^{\mathrm{n} K}=W_{N / m}^{n K / m}
\end{gathered}
$$

According to the characteristics of FFT, the complex calculation is simplified, and the computational efficiency is greatly improved. The calculation amount of complex number multiplication of point $N$ is reduced from $N^{2}$ to $\frac{N}{2} \log _{2}^{N}$ times. The calculation amount is significantly reduced.

\subsection{Envelope spectrum}

Envelope spectrum is a frequency domain analysis method based on spectrum analysis, which is effective in analyzing the frequency of vibration signals. Firstly, the time domain signal is 
demodulated by Hilbert transform, and the extreme value is calculated. Then the envelope is obtained from the one-dimensional data. Finally, Fourier Transform $(F T)$ is performed on the envelope. Unnecessary low-frequency interference is eliminated by envelope spectrum compared with $F F T$ spectrum analysis. The harmonics are more effectively distinguished by the envelope spectrum.

The Hilbert transform of the signal $x(t)$ is defined as:

$$
\hat{x}(t)=\frac{1}{\pi} \int_{-\infty}^{+\infty} \frac{x(\tau)}{t-\tau} d \tau=x(t) \frac{1}{\pi t}
$$

Let $h(t)=1 / \pi t$, performing $F T$ on $h(t)$ :

$$
H(j \omega)=-j \operatorname{sgn}(\omega)= \begin{cases}-j & \omega>0 \\ +j & \omega<0\end{cases}
$$

After the signal is demodulated by Hilbert transform, taking $x(t)$ and $\hat{x}(t)$ as the real part and imaginary part, the analytical signal $\bar{z}(t)$ is:

$$
\bar{z}(t)=x(t)+j \hat{x}(t)
$$

The envelope curve equation of the signal is:

$$
z(t)=|x(t)+j \hat{x}(t)|
$$

\subsection{Wavelet Packet Decomposition}

As the ultrasonic guided waves in the ultrasonic bonding process are non-stationary time-domain signals, it is necessary to study both time-domain and frequency-domain in the process of vibration analysis. WPD is a multi-scale time-frequency local analysis method, which is high resolution for the high-frequency and low-frequency components of signals. The consistency of the time scale is ensured by $W P D$. In wavelet multi-resolution analysis, $L^{2}(R)=\underset{j \in z}{\oplus} W j$ means that the space $L^{2}(R)$ is decomposed into the orthogonal sum of all subspaces $\{W j\} j \in z$ according to different scale factors $j .\{W j\} j \in z$ is the subspace composed of wavelet functions. $L^{2}(R)$ is defined as the spatial function of the vibration signal. The frequency of $\{W j\} j \in z$ space is subdivided in binary form by $d b 2$ wavelet. The decomposed subspace is defined as $U_{j}^{k}$, which represents the $k$-th wavelet packet subspace in $j$ scale, the frequency factor is represented by $k$, $k=0,1, \cdots, 2 j-1$. In this study, the ultrasonic guided wave is decomposed by the three levels wavelet packet, set $j=3$, and the expression of the decomposition is: 


$$
\begin{gathered}
W_{1}=U_{1}^{0} \oplus U_{1}^{1} \\
W_{2}=U_{2}^{0} \oplus U_{2}^{1} \oplus U_{2}^{2} \oplus U_{2}^{3} \\
W_{3}=U_{3}^{0} \oplus U_{3}^{1} \oplus U_{3}^{2} \ldots \oplus U_{3}^{7}
\end{gathered}
$$

The ultrasonic guided wave is decomposed into $2^{3}=8$ subspaces, and the frequency band corresponding to the third layer subspace is:

$$
\left\{\left[0, \frac{f}{2^{j+1}}\right],\left[\frac{f}{2^{j+1}}, \frac{2 f}{2^{j+1}}\right], \Lambda,\left[\frac{\left(2^{j}-1\right) f}{2^{j+1}}, \frac{f}{2}\right]\right\}
$$

$f$ is the sampling frequency.

The sampling frequency of the ultrasonic guided wave is $500 \mathrm{kHz}$, the Nyquist frequency is $250 \mathrm{kHz}$, and the frequency band bandwidth of each subspace is $250 \mathrm{kHz} / 8=31.250 \mathrm{kHz}$.

Let $d i, m(r)$ be the amplitude of each discrete point after reconstruction, where $i$ and $m$ are the frequency factor and decomposition scale, $r$ is the number of discrete sampling points. After three levels of wavelet packet, the energy of each sub-band signal is:

$$
E_{i, 3}=\sum_{r=0}^{n}\left|\mathrm{~d}_{i, 3}(r)\right|^{2}
$$

The energy is normalized when it is large:

$$
E=\sum_{i=0}^{7} E_{i, 3}
$$

The time-frequency characteristics are effectively extracted based on the above-mentioned vibration analysis methods. The harmonic of the ultrasonic guided wave is found by FFT spectrum analysis. The original time-domain signal is decomposed and reconstructed by $W P D$, and the main frequency band position is accurately located by the energy proportion. The harmonic generation $(H G)$, second-harmonics generation $(S H G)$, and third-harmonics generation $(T H G)$ generated by the main frequency band are extracted by spectrum envelope.

\section{Experimental results and analysis}

The precise bonding experiment was carried out based on the test rig. The time-domain waveform of the ultrasonic guided wave is shown in Fig.4. The time range of $0 \sim 2 \mathrm{~s}$ is the initial stage of ultrasonic loading, and the dynamic force amplitude changes significantly. First, the amplitude rises to $0.62 \mathrm{~dB}$, then attenuates to $0.16 \mathrm{~dB}$, finally rises to the peak of $0.87 \mathrm{~dB}$. The amplitude gradually attenuates to $0.2 \mathrm{~dB}$ after reaching the peak. In the time range of $2.5 \mathrm{~s} \sim 5.5 \mathrm{~s}$, 
multiple small peaks continuously appear, and the peaks increase with time. The amplitude is stable at $0.2 \mathrm{~dB}$ after $5.5 \mathrm{~s}$, and the ultrasonic loading is stopped at $9.5 \mathrm{~s}$.

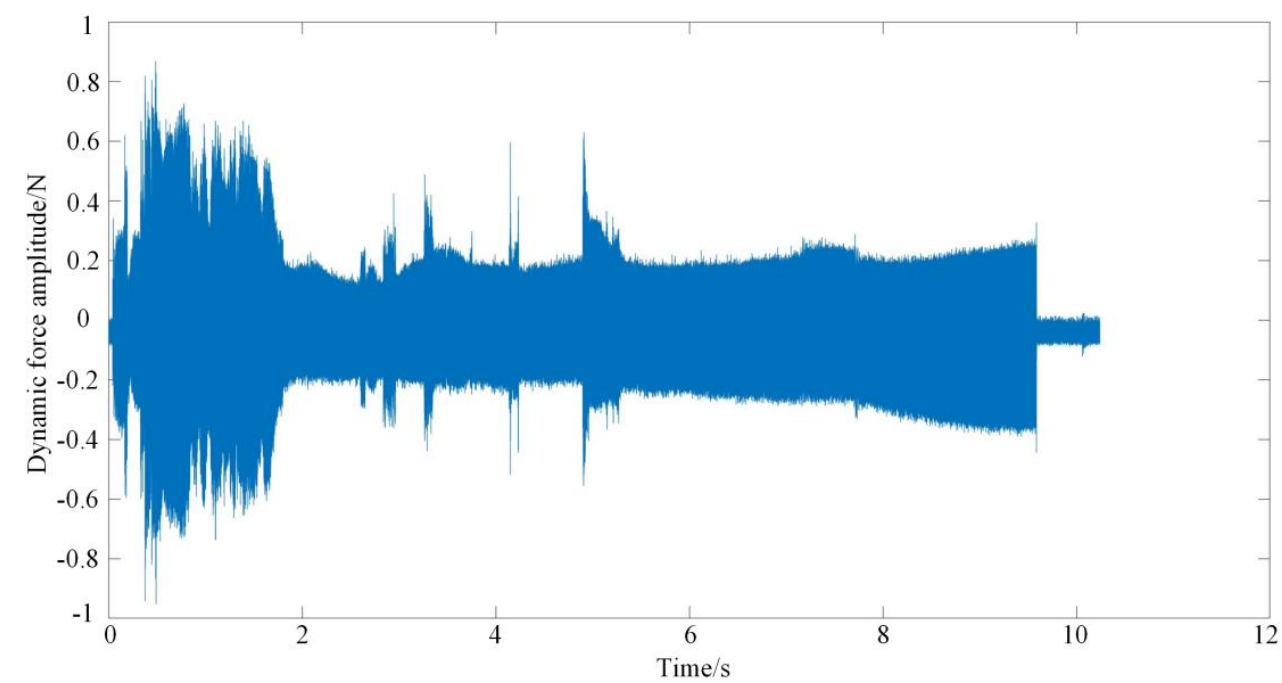

Fig.4. The time-domain waveform of the ultrasonic guided wave

The spectrum of the ultrasonic guided wave by FFT analysis is shown in Fig.5. The frequency range of $F F T$ spectrum analysis is from 0 to $125 \mathrm{kHz}$. The low-frequency noise generated in the experiment is mainly concentrated around $10 \mathrm{kHz}$. The main frequency is concentrated at $60 \mathrm{kHz}$, and the maximum amplitude reaches $1.3 \times 10^{5} \mathrm{~dB}$.

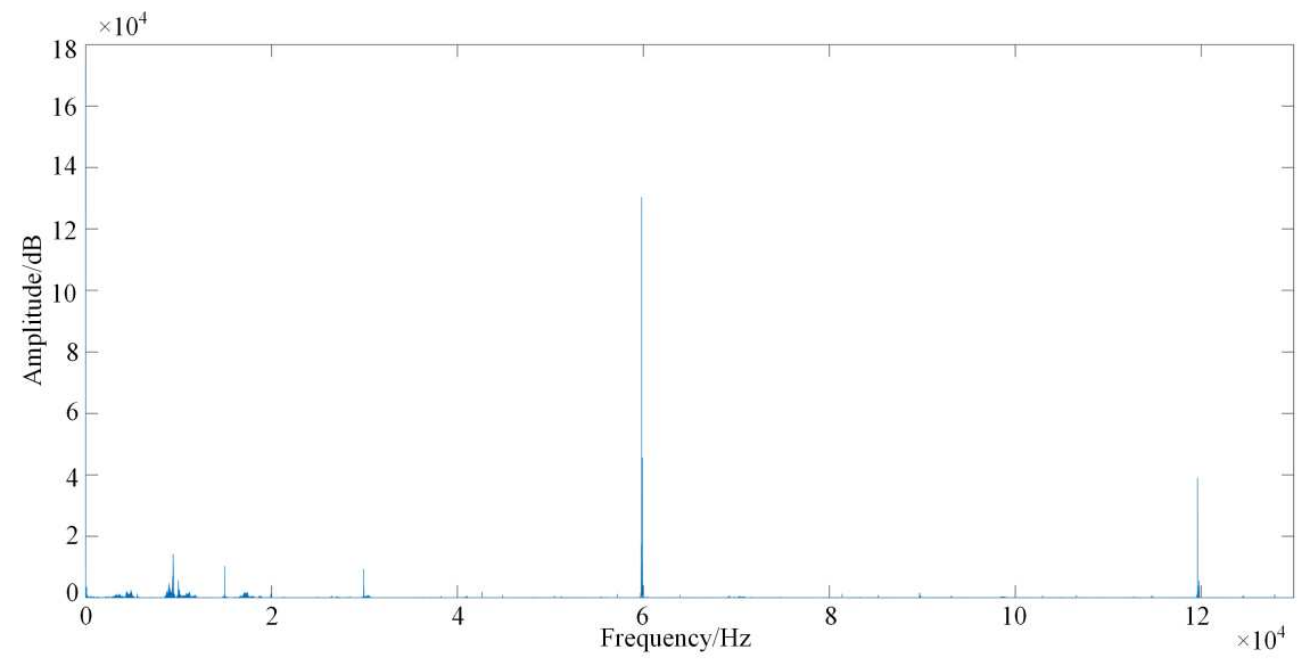

Fig.5. The spectrum of the ultrasonic guided wave

The frequency characteristics of the $60 \mathrm{kHz}$ main frequency band are studied. The frequency spectrum of the ultrasonic guided wave is processed by band-pass filtering to obtain the frequency spectrum of the $60 \mathrm{kHz}$ frequency band. The frequency spectrum of the main frequency band around $60 \mathrm{kHz}$ from $54 \mathrm{kHz}$ to $66 \mathrm{kHz}$ is shown in Fig.6. 


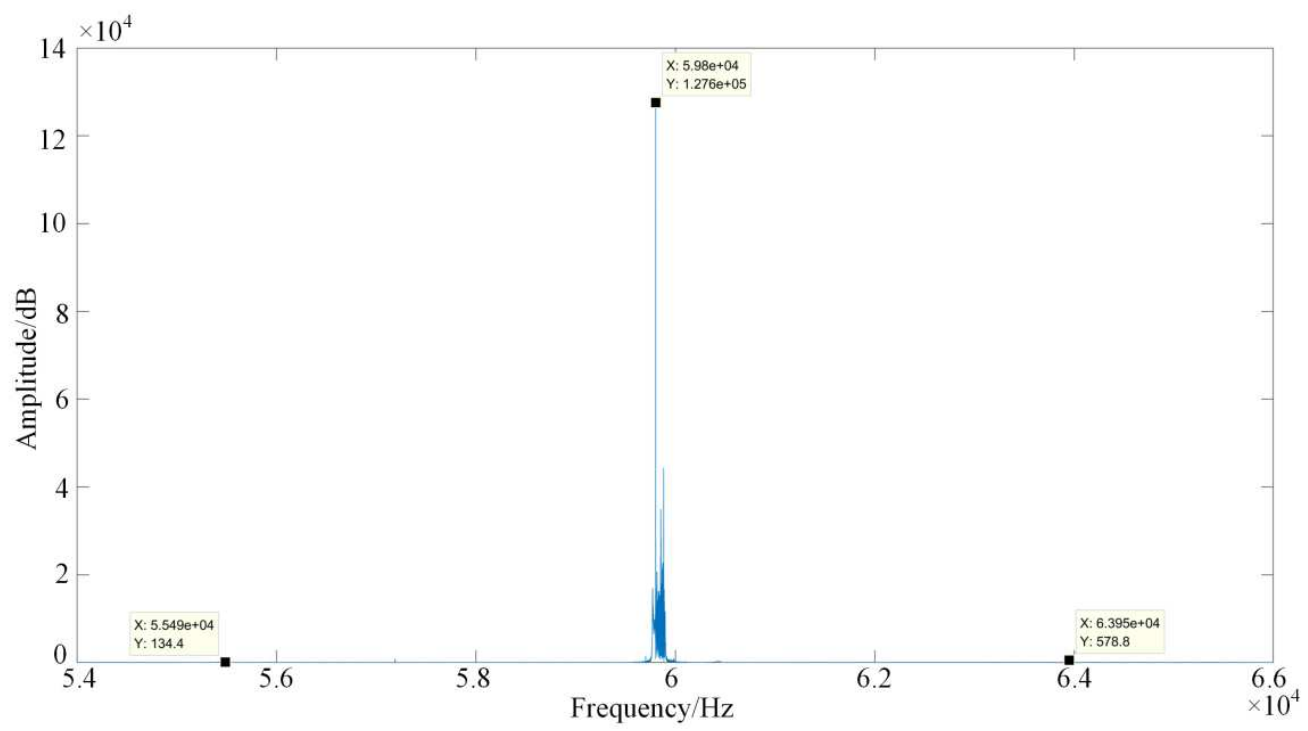

Fig.6. The frequency spectrum of the $60 \mathrm{kHz}$ main frequency band

From Fig.6, the main frequency of the ultrasonic guided wave is $59.8 \mathrm{kHz}$, and the frequency amplitude is as high as $127.6 \mathrm{kdB}$. The harmonic is generated by the $60 \mathrm{kHz}$ main frequency band, the amplitude of which is smaller than the main frequency amplitude. The harmonic is symmetrical around the main frequency. The frequency of the left characteristic point is $55.49 \mathrm{kHz}$, the amplitude is $134.4 \mathrm{~dB}$, and the right ones are $63.95 \mathrm{kHz}$ and $538.8 \mathrm{~dB}$.

The time-domain waveform of the ultrasonic guided wave is decomposed by three levels wavelet packet. The entire frequency-domain is divided into eight segments on average. The energy distribution proportion of each frequency band is shown in Tab.1.

Tab.1. The energy distribution proportion of each frequency band

\begin{tabular}{|c|c|c|c|c|c|c|c|c|c|}
\hline \multirow{2}{*}{ Parameter } & \multicolumn{9}{|c|}{ node } \\
\hline & 0.0 & 3.0 & 3.1 & 3.2 & 3.3 & 3.4 & 3.5 & 3.6 & 3.7 \\
\hline $\begin{array}{l}\text { Frequency } \\
\text { band/kHz }\end{array}$ & $\begin{array}{c}0 \sim \\
250.000\end{array}$ & $\begin{array}{c}0 \sim \\
31.250\end{array}$ & $\begin{array}{c}31.250 \sim \\
62.500\end{array}$ & $\begin{array}{c}62.500 \sim \\
93.750\end{array}$ & $\begin{array}{l}93.750 \sim \\
125.000\end{array}$ & $\begin{array}{c}125.000 \sim \\
156.260\end{array}$ & $\begin{array}{c}156.260 \sim \\
187.500\end{array}$ & $\begin{array}{c}187.500 \sim \\
218.750\end{array}$ & $\begin{array}{c}218.750 \sim \\
250.000\end{array}$ \\
\hline Energy/J & 124120 & 28647 & 48169 & 38951 & 1987.8 & 1591.7 & 2184.9 & 2540.3 & 43.3471 \\
\hline $\begin{array}{c}\text { energy } \\
\text { proportion/ } \\
\%\end{array}$ & 100.000 & 23.080 & 38.810 & 31.380 & 1.602 & 1.282 & 1.760 & 2.470 & 0.000 \\
\hline
\end{tabular}

The frequency energy is mainly distributed in the three frequency bands of $[0 \sim 31.250] \mathrm{kHz}$, $[31.250 \sim 62.500] \mathrm{kHz}$, and [62.500 93.750]kHz. The energy distribution proportions are $23.08 \%$, $38.81 \%$, and $31.38 \%$ respectively. The remaining nodes are ignored due to relatively low energy.

The characteristic waveforms in the frequency bands of $[31.250 \sim 62.500] \mathrm{kHz}$ and $[62.500 \sim 93.750] \mathrm{kHz}$ are reconstructed. The reconstructed characteristic waveforms are shown in 
Fig.7 and Fig.8. From the two waveforms, the amplitude changing trends are the same. In the time range of $0 \sim 1.8 \mathrm{~s}$, the dynamic force amplitude increases sharply to about $1 \mathrm{~dB}$ and then attenuates to $0.35 \mathrm{~dB}$. The reason is that high-frequency vibration of the thermal melt interface occurs when ultrasound is loaded, the bonding interface is no longer in the glass state, and the amplitude changes significantly. In the time range of $1.8 \mathrm{~s} \sim 2.9 \mathrm{~s}$, the amplitude attenuates to $0.24 \mathrm{~dB}$ when the thermal melt interface is melted locally. In the time range of $2.9 \mathrm{~s} \sim 9.5 \mathrm{~s}$, the melting of the thermal melt interface requires continuous absorption of energy, and the amplitude increases slightly.

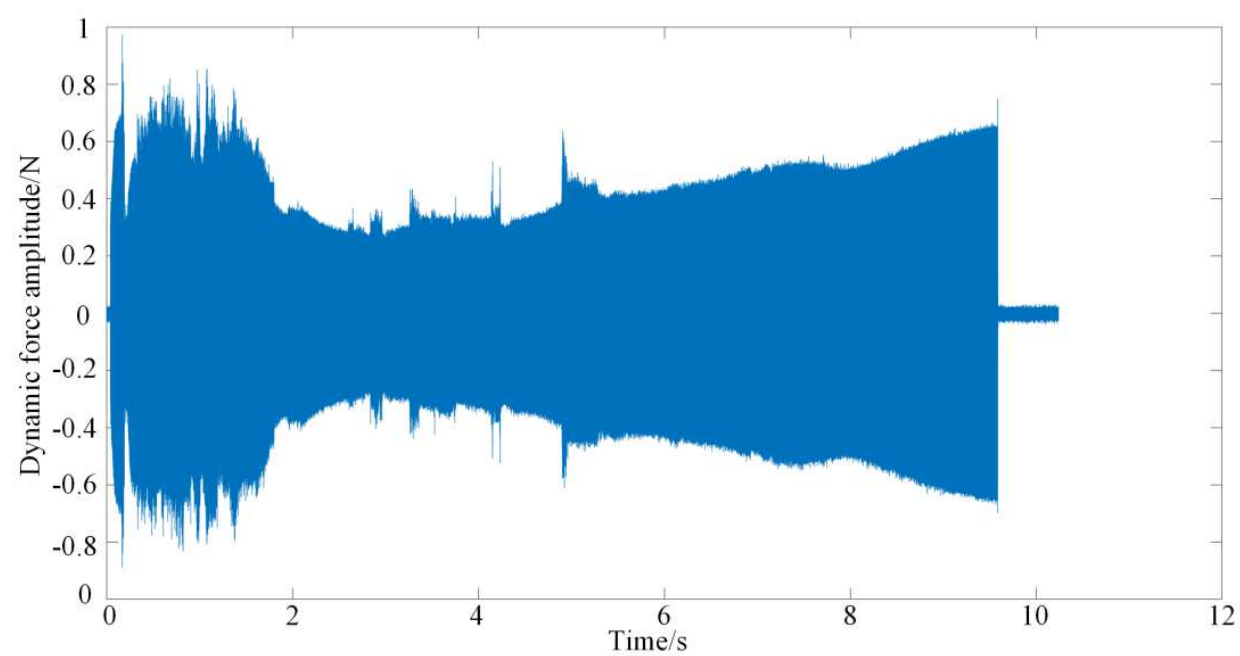

Fig.7. The characteristic waveform of [31.250 62.500]kHz frequency band

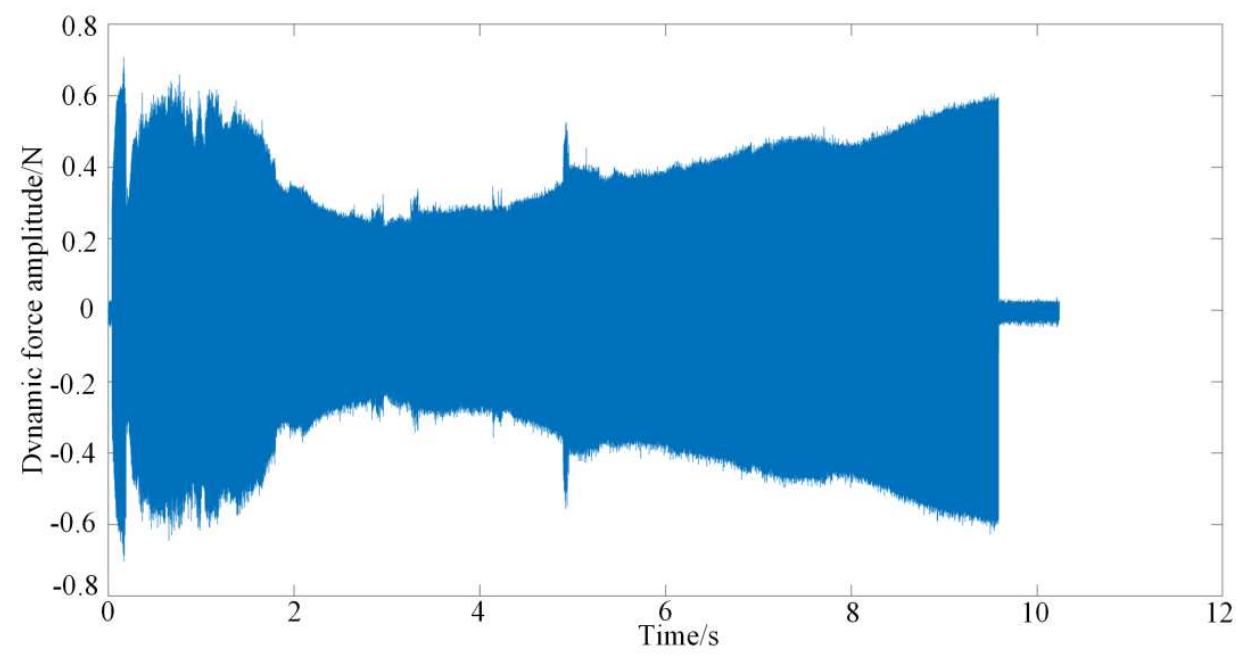

Fig.8. The characteristic waveform of [62.500 93.750]kHz frequency band

The envelope spectrum of the characteristic waveform of the $60 \mathrm{kHz}$ main frequency band is shown in Fig.9. The frequency range of the envelope spectrum is from 0 to $120 \mathrm{kHz}$. The $H G, S H G$, and $T H G$ are generated by the $60 \mathrm{kHz}$ main frequency band. 


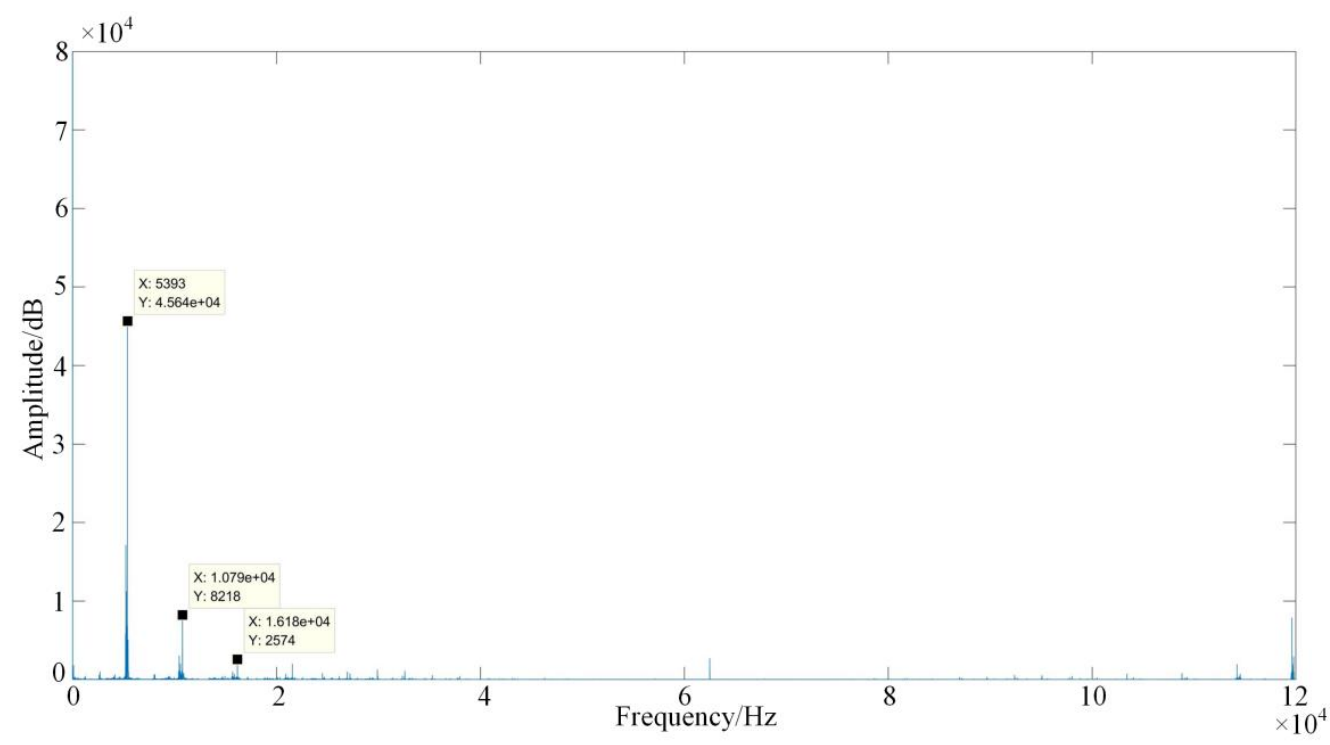

Fig.9. The envelope spectrum of the characteristic waveform in the $60 \mathrm{kHz}$ main frequency band

The frequency of the $H G, S H G$, and $T H G$ are $5.393 \mathrm{kHz}, 10.790 \mathrm{kHz}$, and $16.180 \mathrm{kHz}$. The corresponding amplitudes are $45640 \mathrm{~dB}, 8218 \mathrm{~dB}$, and $2574 \mathrm{~dB}$ respectively. The amplitudes of the frequencies from $20 \mathrm{kHz}$ to $40 \mathrm{kHz}$ are all below $2000 \mathrm{~dB}$, and there is no regularity between them. The frequency greater than $60 \mathrm{kHz}$ does not meet the characteristics of the harmonic, which are not considered.

The $H G, S H G$, and $T H G$ time-frequency characteristics in the ultrasonic guided wave are processed by the vibration analysis algorithm. The three-dimensional diagram of the $H G, S H G$, and $T H G$ time-frequency characteristics is shown in Fig.10. The $\mathrm{x}$-axis is the time $(s)$ of ultrasonic loading, the y-axis is the frequency $(H z)$, and the z-axis is the frequency intensity $(d B)$. The $H G$, $S H G$, and $T H G$ positions are marked in Fig.10. The ultrasonic loading time is $9.5 \mathrm{~s}$, and the frequency range is 0 to $20 \mathrm{kHz}$.

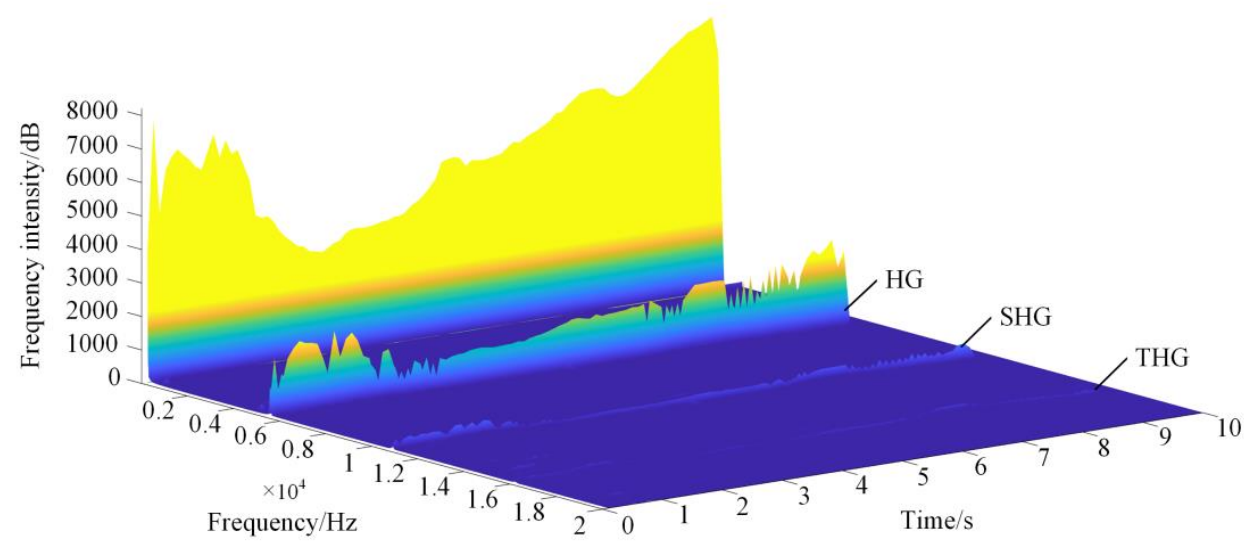

Fig.10. The three-dimensional diagram of the $H G, S H G$, and $T H G$ time-frequency characteristics 
From Fig.10, it is found that the trends of the $H G, S H G$, and $T H G$ are the same as the original waveform. They are all shown the trend of increasing-decreasing-increasing within $0 \sim 9.5 \mathrm{~s}$. In the time range of $0 \sim 2.8 \mathrm{~s}$, the $H G, S H G$, and $T H G$ frequency intensities vary significantly, which the peaks are $2374 \mathrm{~dB}, 396.2 \mathrm{~dB}, 221.4 \mathrm{~dB}$, and the troughs are $757.7 \mathrm{~dB}, 113.9 \mathrm{~dB}, 27.7 \mathrm{~dB}$ respectively. In the time range of $2.8 \mathrm{~s} \sim 9.5 \mathrm{~s}$, the frequency intensity of $\mathrm{HG}, \mathrm{SHG}$, and THG increase in general.

To obtain the time-frequency characteristics in ultrasonic guided waves more clearly, the three-dimensional diagram is converted into two-dimensional diagrams. The time-harmonic frequency characteristics diagram and the time-harmonic frequency intensity characteristics diagram are shown in Fig.11 and Fig.12. The range of frequency intensity is truncated to $3000 \mathrm{~dB}$ to study the characteristics of Fig.12 in more detail due to the $H G$ maximum frequency intensity is $2886 \mathrm{~dB}$.

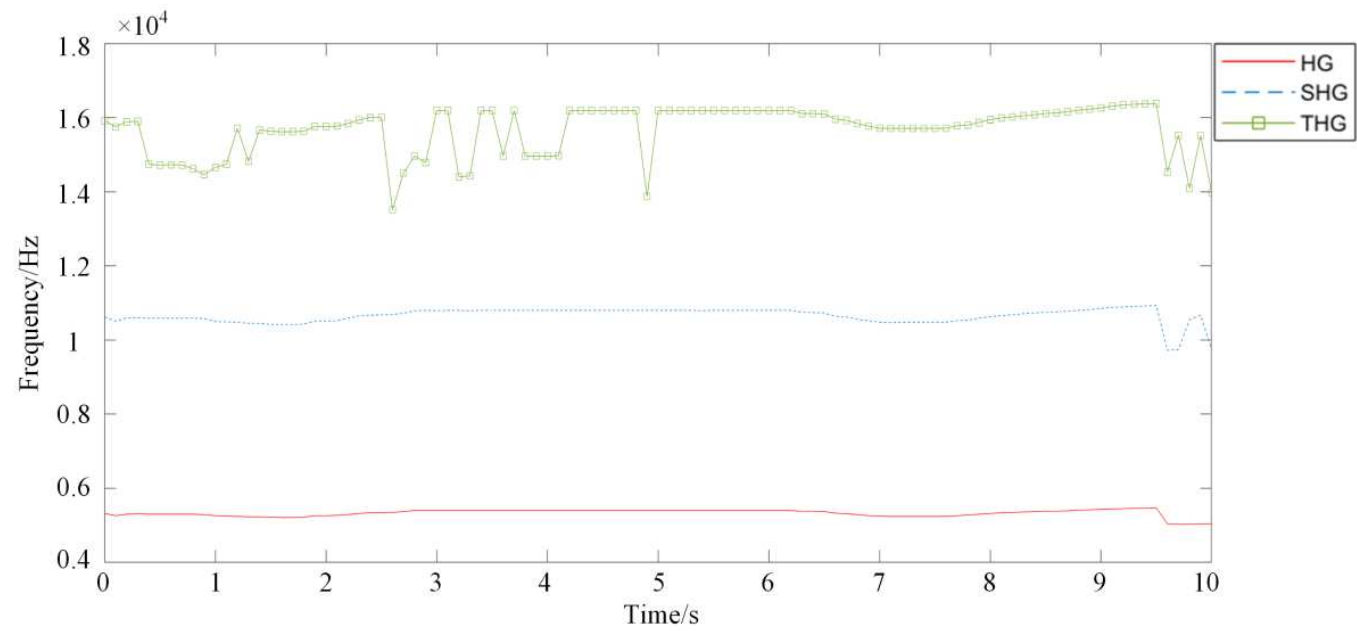

Fig.11 The time-harmonic frequency characteristics diagram

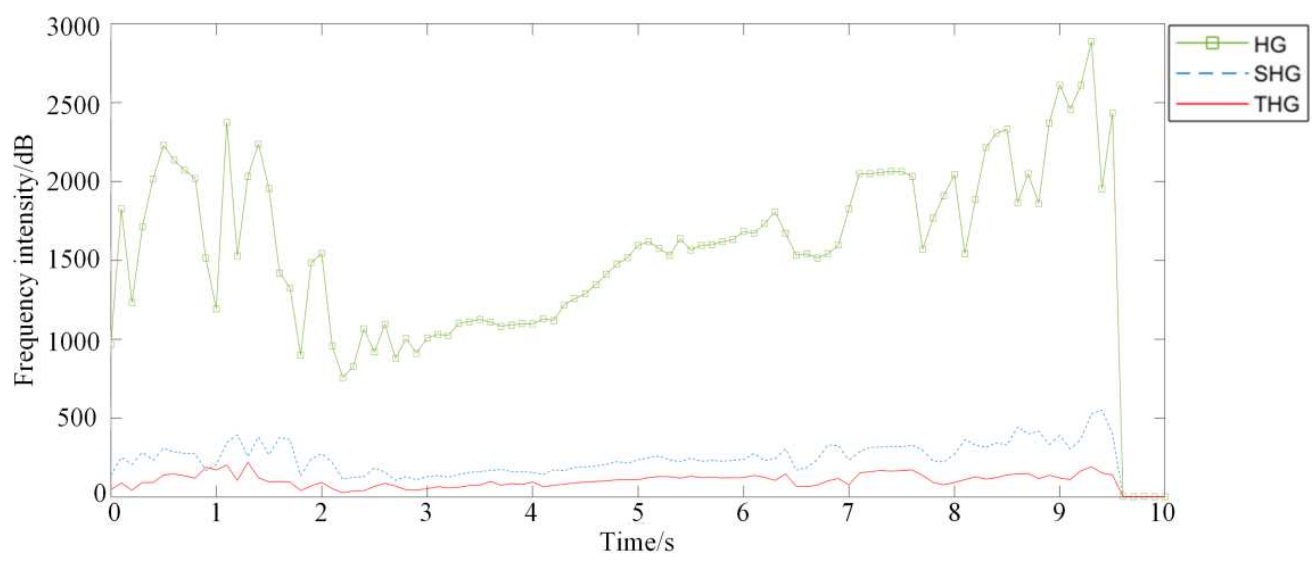

Fig.12. The time-harmonic frequency intensity characteristics diagram

From Fig.11, it is found that the frequency trends of the $H G$ and $S H G$ are the same within $0 \sim 9.5 \mathrm{~s}$. In the time range of $0 \sim 2.8 \mathrm{~s}$, the frequency of $H G$ and $S H G$ shows a trend of decreasing first and then increasing, which attenuate to $5.220 \mathrm{kHz}$ and $10.430 \mathrm{kHz}$ respectively at $1.8 \mathrm{~s}$. The $T H G$ frequency attenuates from $15.900 \mathrm{kHz}$ to $14.740 \mathrm{kHz}$ at $0.4 \mathrm{~s}$, and from $16.010 \mathrm{kHz}$ to 
$13.510 \mathrm{kHz}$ at $2.6 \mathrm{~s}$. In the time range of $2.8 \mathrm{~s} \sim 6.2 \mathrm{~s}$, the $H G$ and $S H G$ frequency remains at $5.400 \mathrm{kHz}$ and $10.800 \mathrm{kHz}$ respectively. The $T H G$ maximum frequency is $16.190 \mathrm{kHz}$, and the minimum is $13.870 \mathrm{kHz}$ at $4.9 \mathrm{~s}$. In the time range of $6.2 \mathrm{~s} \sim 7 \mathrm{~s}$, the $H G, S H G$, and $T H G$ frequencies attenuate to $5240 \mathrm{kHz}, 10.470 \mathrm{kHz}$, and $15.710 \mathrm{kHz}$ respectively. In the time range of $7 \mathrm{~s} \sim 7.6 \mathrm{~s}$, the $H G, S H G$, and $T H G$ frequency remain at $5.240 \mathrm{kHz}, 10.480 \mathrm{kHz}$, and $15.71 \mathrm{kHz}$ respectively. In the time range of $7.6 \mathrm{~s} \sim 9.5 \mathrm{~s}$, the $H G, S H G$, and $T H G$ frequency are all increased slightly. From Fig.12, it is found that the range of the $H G$ frequency intensity is $757.7 \mathrm{~dB}$ to $2886 \mathrm{~dB}$, the $S H G$ is $106.2 \mathrm{~dB}$ to $552.8 \mathrm{~dB}$, and the $T H G$ is $27.7 \mathrm{~dB}$ to $221.4 \mathrm{~dB}$. The $H G$ and $T H G$ frequency intensity is decreased at $0.9 \mathrm{~s}$ and $3.6 \mathrm{~s}$, while the $S H G$ is increased. The $H G$ and $T H G$ frequency intensity is increased at $1.2 \mathrm{~s}$, while the $S H G$ is decreased. The $S H G$ and $T H G$ frequency intensity is increased at $4.2 \mathrm{~s}$, while the $H G$ is decreased. The trends of $H G, S H G$, and $T H G$ frequency intensity are the same after $4.2 \mathrm{~s}$.

The interfacial thermal melt state is monitored and recorded online by a high-speed HD camera. Eight characteristic points are extracted according to the interfacial thermal melt state characteristics of the thermal melt interface during the ultrasonic bonding process. The thermal melt interface is unbonded at the start. The interface of the micro-device starts to change under the ultrasonic load. Eight characteristic points of the thermal melt interface are shown in Fig.13.

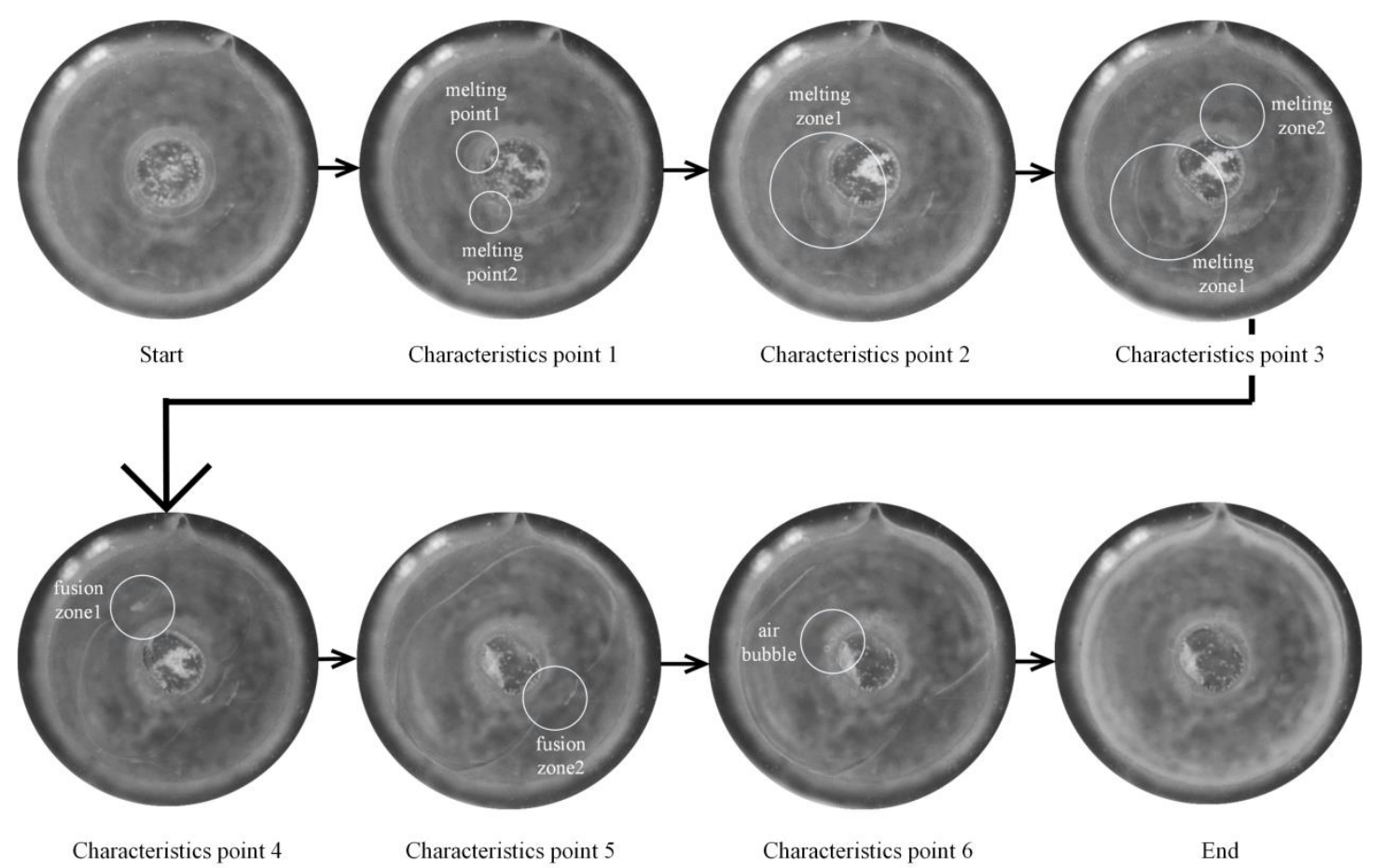

Fig.13. The thermal melt interface of the micro-device

From characteristics point 1 , it is found that the melting points 1 and 2 appear in the random position on the thermal melt interface. In this case, it emerges from the bottom left of the thermal melt interface. The reason is that in the initial stage of ultrasonic loading, the heat generated by the friction of contacting surfaces under high-frequency vibration and is irregularly distributed due to the difference and random distribution of the surface roughness, melting points appear randomly. At characteristics point 2 , the melting points 1 and 2 generate melting zone 1 , and continue to 
spread. At characteristics point 3, a new melting zone 2 is generated, which is located at the upper right of the thermal melt interface. At characteristics points 4 and 5, the melting zones 1 and 2 are respectively fused to generate fusion zones 1 and 2. At characteristics point 6 , dense air bubbles are generated on the thermal melt interface. The reason is that the high-frequency reciprocating motion of the thermal melt interface causes the temperature to rise, and the micro-device interface turns into a viscous flow state, resulting in the ultrasound cavitation effect. The thermal melt interface is fully fused at the end.

In the starting, the thermal melt interface is in a glassy state, and the temperature of the interface rises under the ultrasound load. The thermal melt interface is transformed from a glass state to a high elastic state, and melting zones appear when the temperature reaches the $T_{g}$. The high elastic state is transformed to the viscous flow state, and the thermal melt interface melts in a large area when the temperature further rises to the viscous flow temperature $\left(T_{f}\right)$.

The interfacial fusion process is studied together with the $H G, S H G$, and $T H G$ time-frequency characteristics in the ultrasonic guided wave. The correlation of thermal melt state and time-harmonic frequency is shown in Fig.14. The correlation of thermal melt state and time-harmonic frequency intensity is shown in Fig.15. The two diagrams are respectively divided into seven stages based on eight time-frequency characteristics points in Fig.13.

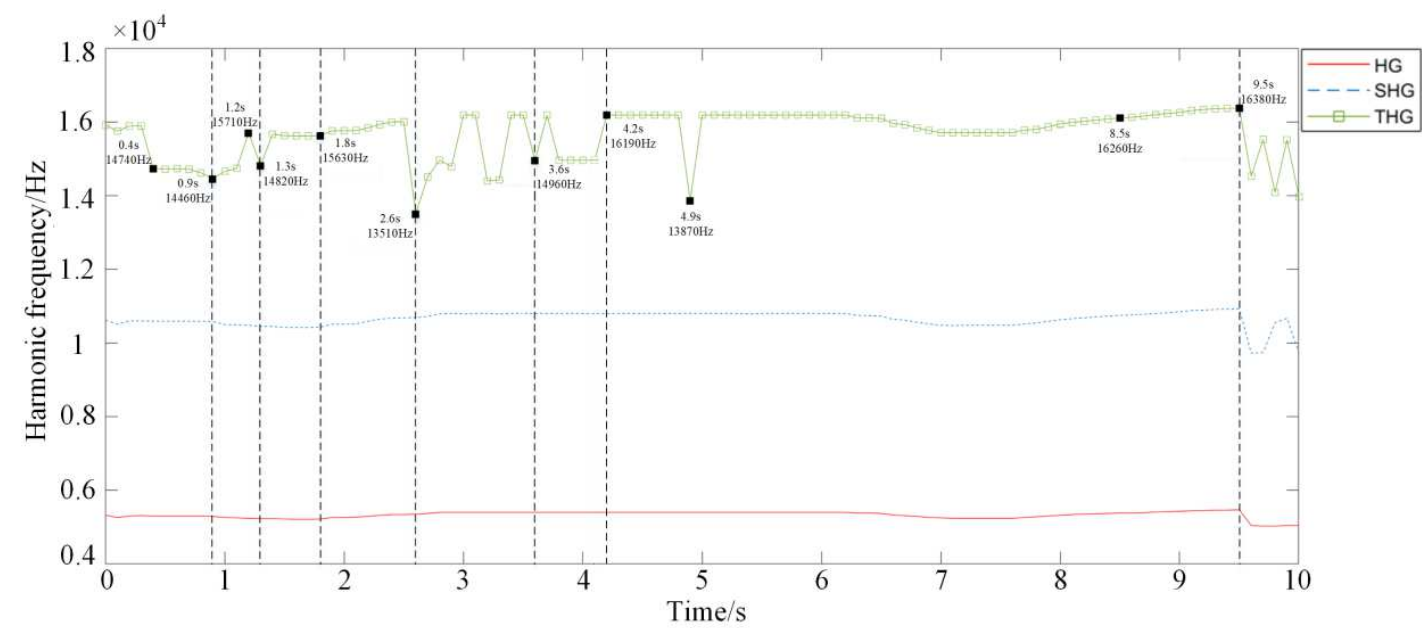

Fig.14. The correlation of thermal melt state and time-harmonic frequency 


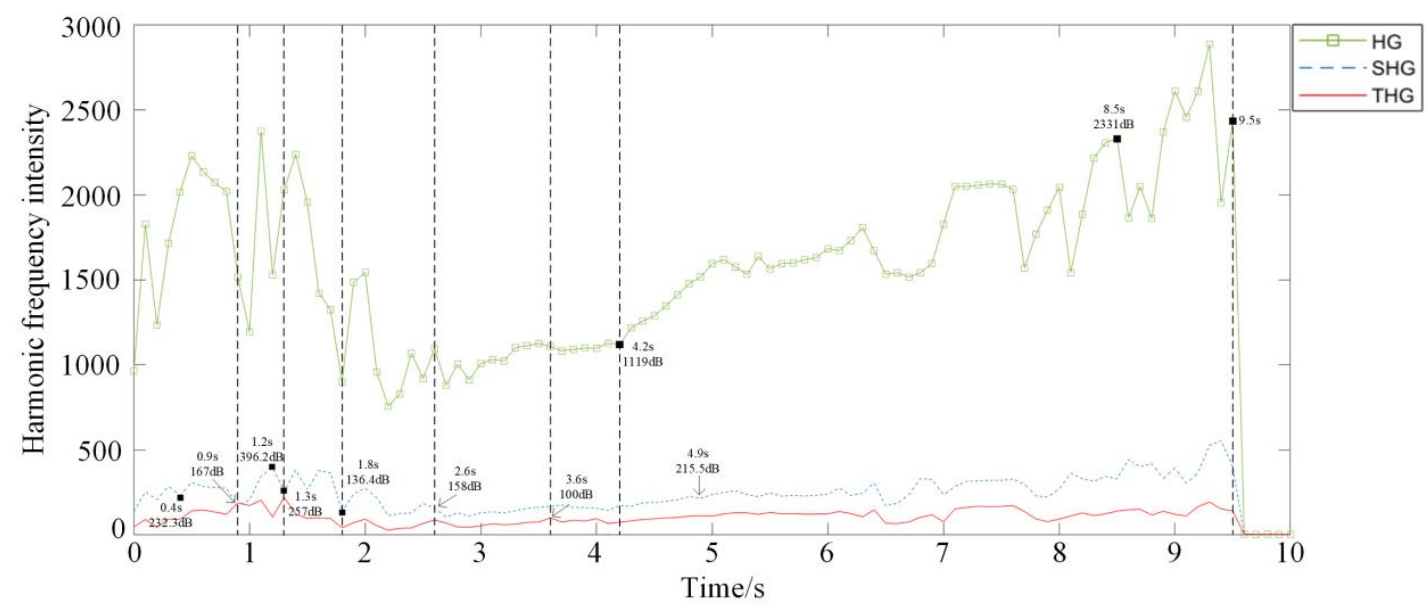

Fig.15. The correlation of thermal melt state and time-harmonic frequency intensity

From stage $\mathrm{I}$ in the range of $0 \sim 0.9 \mathrm{~s}$, it is found that the $T H G$ frequency changes from $15.900 \mathrm{kHz}$ to $14.740 \mathrm{kHz}$ at $0.4 \mathrm{~s}$, the $S H G$ frequency intensity decreases from $286.8 \mathrm{~dB}$ to 232.3 $\mathrm{dB}$. The micro-device starts to rotate at this time. The $T H G$ frequency changes from $14.620 \mathrm{kHz}$ to $14.460 \mathrm{kHz}$ at $0.9 \mathrm{~s}$, and the intensity increases from $120.8 \mathrm{~dB}$ to $189.3 \mathrm{~dB}$. Melting points 1 and 2 are randomly generated on the thermal melt interface at $0.9 \mathrm{~s}$.

From stage II in the range of $0.9 \mathrm{~s} \sim 1.3 \mathrm{~s}$, the $T H G$ frequency rises to $15.710 \mathrm{kHz}$ at $1.2 \mathrm{~s}$ and decreases to $14.820 \mathrm{kHz}$ at $1.3 \mathrm{~s}$. The $S H G$ frequency intensity rises to a small peak of $396.2 \mathrm{~dB}$ at $1.2 \mathrm{~s}$. The $T H G$ frequency intensity rises to a small peak of $221.4 \mathrm{~dB}$ at $1.3 \mathrm{~s}$. The rotation process of the micro-device and the fusion process of melting zone 1 are shown in Fig.16 and Fig.17.
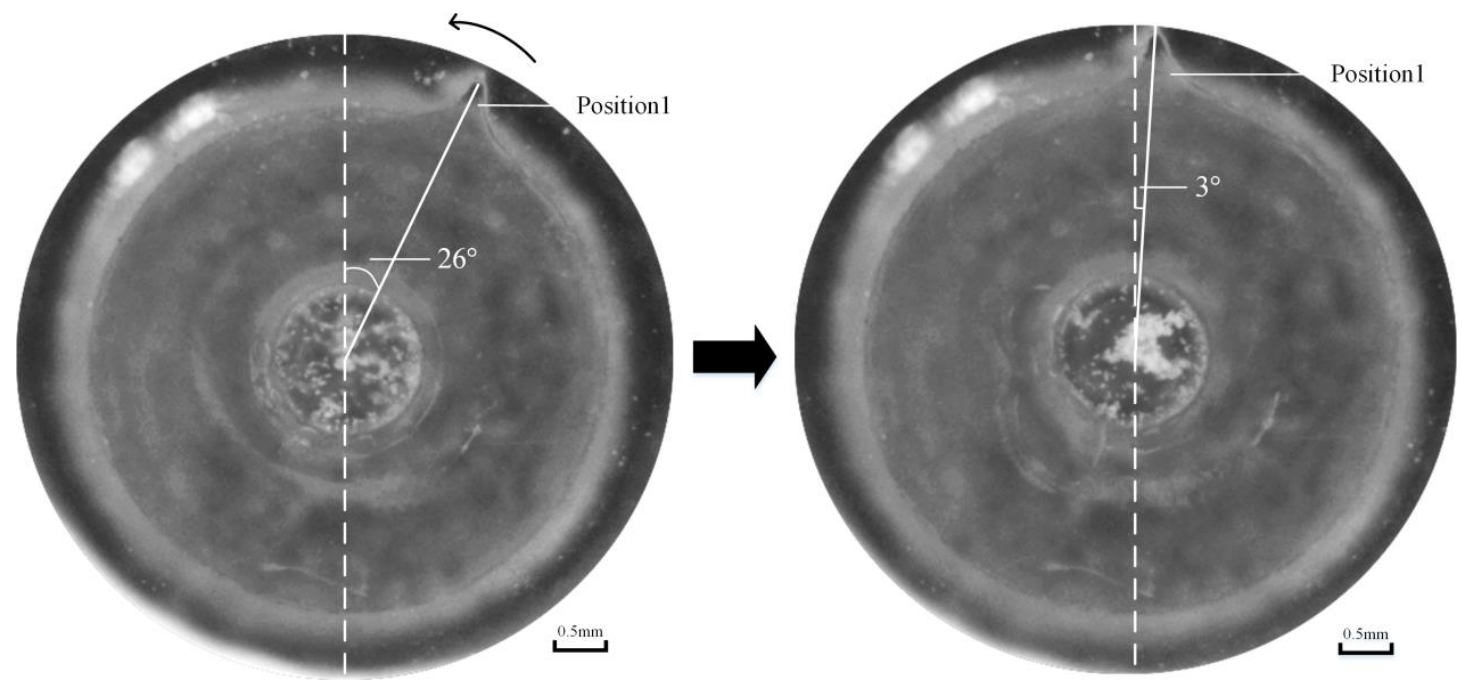

Fig.16. The rotation process of the micro-device 


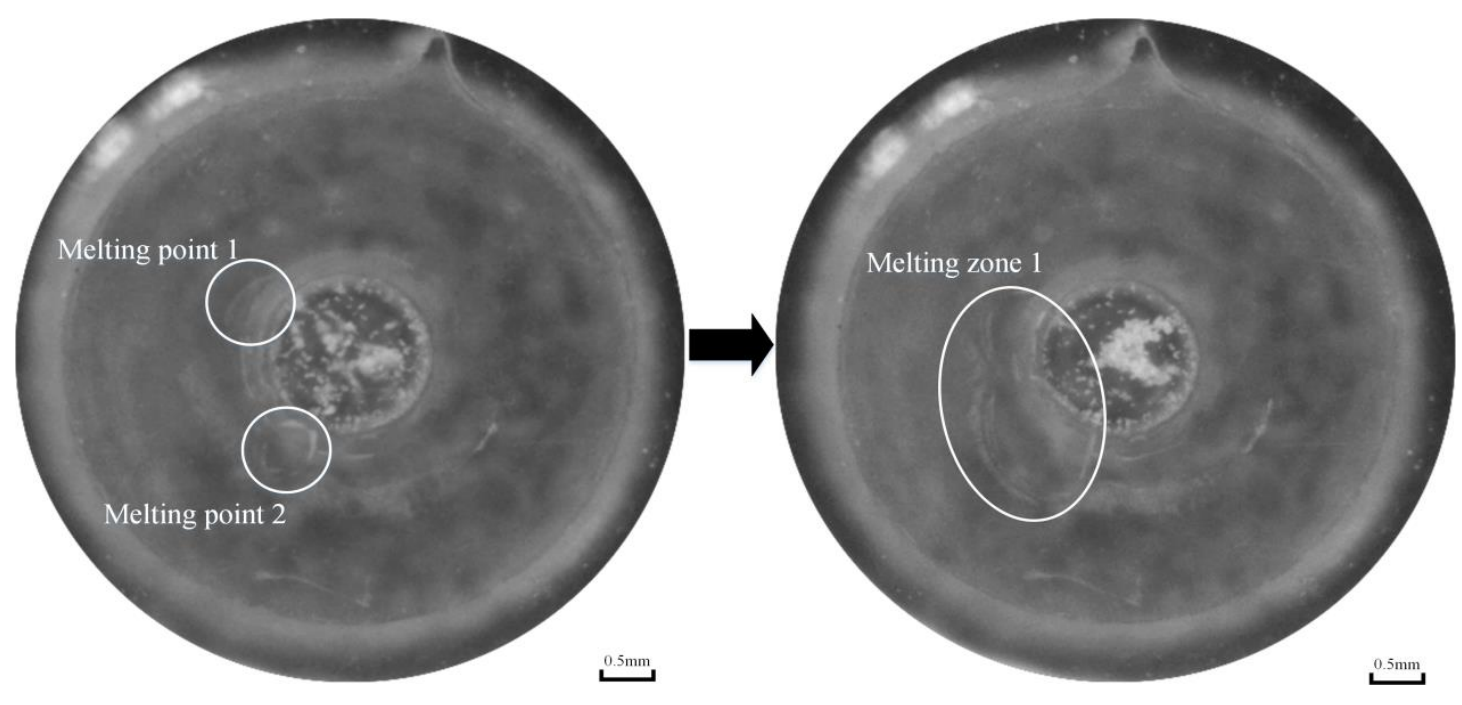

Fig.17. The fusion process of melting zone 1

From Fig. 16, it is found that the micro-device remains motionless before $0.4 \mathrm{~s}$, and position 1 forms an angle of $26^{\circ}$ with the centerline. The micro-device starts to rotate from $0.4 \mathrm{~s}$ and stops rotating at $1.2 \mathrm{~s}$. Rotation with an angle of $3^{\circ}$ with the centerline occurs in position 1. From Fig.17, it is found that there are two small-zone melting points 1 and 2 on the left side of the thermal melt interface, which gradually spread to the surrounding under the ultrasonic load. Melting points 1 and 2 generate melting zone 1 at $1.3 \mathrm{~s}$.

From stage III in the range of $1.3 \mathrm{~s} \sim 1.8 \mathrm{~s}$, the melting zone 1 spreads uniformly around. The $H G$, $S H G$, and $T H G$ frequency is stable at $5.210 \mathrm{kHz}, 10.420 \mathrm{kHz}$, and $15.670 \mathrm{kHz}$, and the frequency intensity is $900.1 \mathrm{~dB}, 136.4 \mathrm{~dB}$, and $42.2 \mathrm{~dB}$ respectively at $1.8 \mathrm{~s}$.

From stage IV in the range of $1.8 \mathrm{~s} \sim 2.6 \mathrm{~s}$, the trends of the $H G, S H G$, and $T H G$ frequency are increased. The melting zone 2 is generated at the upper right of the thermal melt interface at $1.8 \mathrm{~s}$, and then the melting zones 1 and 2 spread around together. At 2.6s, the $T H G$ frequency attenuates sharply from $16.010 \mathrm{kHz}$ to $13.510 \mathrm{kHz}$, and the $H G$ and $T H G$ frequency intensity is the small peak. The melting zones 1 and 2 are locally fused. The local fusion process is shown in Fig.18.
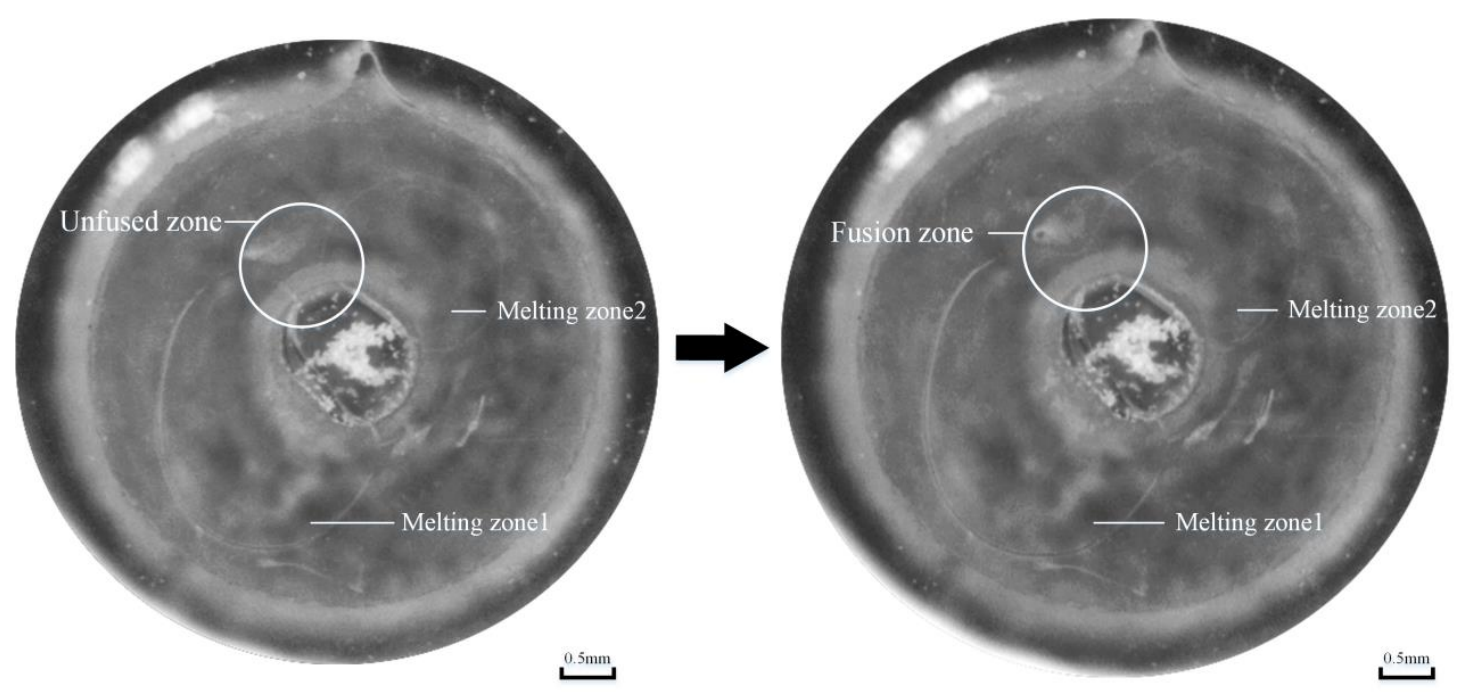
Fig.18. The local fusion process of melting zones 1 and 2

From Fig.18, it is found that the melting zones 1 and 2 are partially fused at the upper left of the thermal melt interface at $2.6 \mathrm{~s}$, then the local fusion zone is further spread from the center to the edge. There is another unfused zone at the bottom right of the thermal melt interface.

From stage $\mathrm{V}$ in the range of $2.6 \mathrm{~s} \sim 3.6 \mathrm{~s}$, the $T H G$ frequency attenuates from $16.190 \mathrm{kHz}$ to $14.960 \mathrm{kHz}$ at 3.6s. The $H G$ and $T H G$ frequency intensity is decreased to $1109 \mathrm{~dB}$ and $100.5 \mathrm{~dB}$ respectively, while the $S H G$ increased to $176 \mathrm{~dB}$. The melting zones 1 and 2 are completely fused at $3.6 \mathrm{~s}$.

From stage VI in the range of $3.6 \mathrm{~s} \sim 4.2 \mathrm{~s}$, a large area of the melting zone is generated on the thermal melt interface. The bonding process entered the mid-term. At $4.2 \mathrm{~s}$, the $T H G$ frequency rises from $14.970 \mathrm{kHz}$ to $16.190 \mathrm{kHz}$. The $H G$ frequency intensity is the peak, while the $S H G$ and $T H G$ frequency intensity is the troughs. Dense air bubbles begin to appear on the thermal melt interface at this time.

From stage VII in the range of $4.2 \mathrm{~s} \sim 9.5 \mathrm{~s}$, which is the later stage of the bonding process. The $H G, S H G$, and $T H G$ frequency is stable at $5.400 \mathrm{kHz}, 10.800 \mathrm{kHz}$, and $16.000 \mathrm{kHz}$ respectively. The $T H G$ frequency attenuates sharply to $13.870 \mathrm{kHz}$ at $4.9 \mathrm{~s}$, and the intensity rises from $1477 \mathrm{~dB}$ to $1517 \mathrm{~dB}$. The $S H G$ frequency intensity attenuates from $225 \mathrm{~dB}$ to $215.5 \mathrm{~dB}$, and the $T H G$ does not change obviously. The disappearance process of local air bubbles on the thermal melt interface is shown in Fig.19.
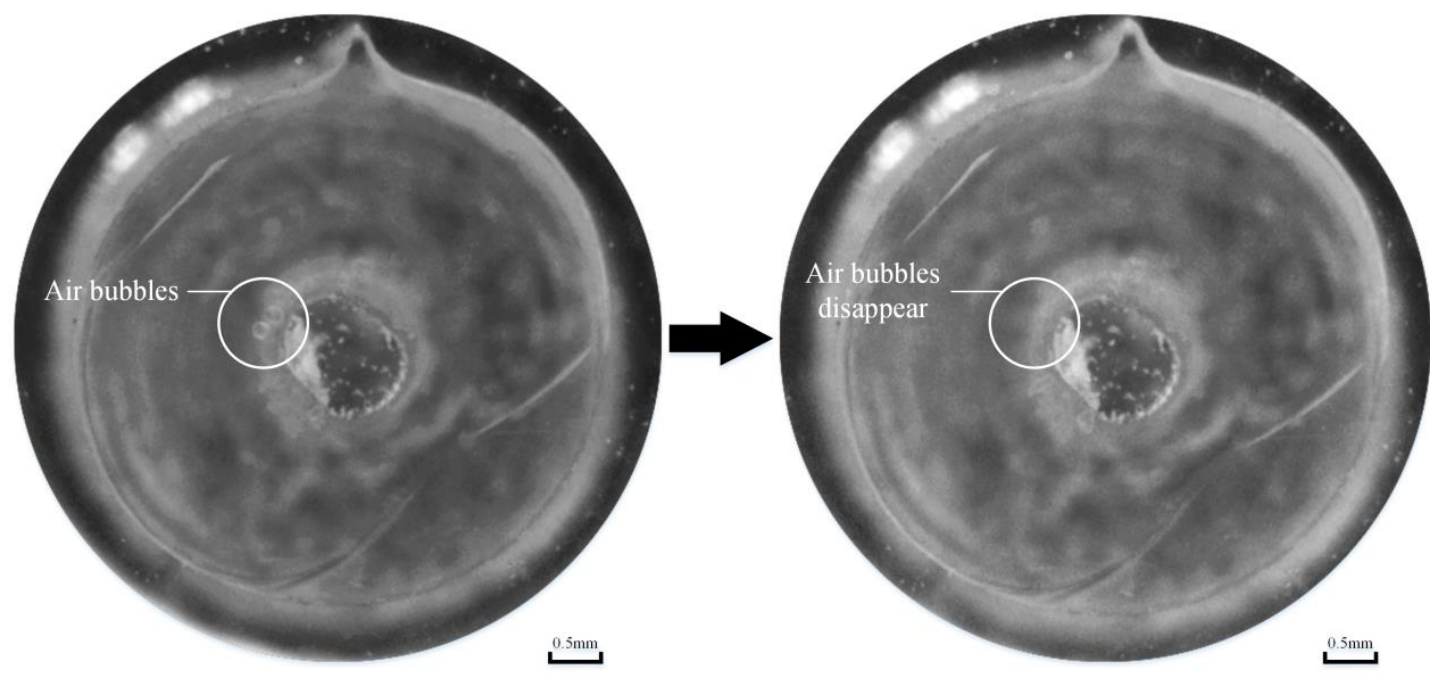

Fig.19. The disappearance process of local air bubbles on the thermal melt interface

From Fig.19, it is found that some local air bubbles appear at the upper left of the thermal melt interface starting from 4.2s. Under the ultrasonic load, the number and diameter of local air bubbles are increased. At $4.9 \mathrm{~s}$, the air bubbles with increasing cavity area rupture, and disappear at the upper left of the thermal melt interface.

The thermal melt interface is completely fused at $8.5 \mathrm{~s}$, and the micro-device interface no longer changes. The ultrasonic loading is stopped at $9.5 \mathrm{~s}$, the micro-device bonding process is ended. 


\section{5. conclusion}

The correlation between the time-frequency characteristics in the ultrasonic guided wave and the interfacial thermal melt state during the polymer ultrasonic bonding process is studied. The interfacial thermal melt state change process is monitored online by the high-speed HD camera, and the time-frequency characteristics are extracted by the vibration analysis algorithm based on FFT spectrum analysis, WPD, and envelope spectrum. The results show that the fusion of melting zones, the rotation of micro-devices, and the generation or disappearance of air bubbles all affect the time-frequency characteristics, resulting in the frequency and intensity of $H G, S H G$, and $T H G$ changing. The characteristic components of ultrasonic guided waves are effective parameters for in-situ monitoring of the fusion degree of the thermal melt interface.

Authors' contributions Sun YB was responsible for the formulation of the overall plan. Cao MR was responsible for the experimental part. Zou L was responsible for the data analysis. Yang XH was responsible for the development of the detection system.

Funding This work was supported by Liaoning Province "Xingliao Talent Program" project for young top talents (XLYC1807112)

General program funding for the China Postdoctoral Science Foundation (2019M651103)

The National Science Foundation of China under Grant (52005071)

Availability of data and materials The authors declare that the data and the materials of this study are available within the article.

\section{Declarations}

Ethics approval Not applicable.

Consent to participate Informed consent was obtained from all individual participants included in the study.

Consent for publication The participants have consented to the submission of the case report to the journal.

\section{References}

[1] West J, Becker M, Tombrink S, Manz A (2008) Micro total analysis systems: Latest achievements. Anal. Chem 80:4403-4419. https://doi.org/10.1021/ac800680j

[2] Liu C (2007) Recent developments in polymer MEMS. Adv. Mater 19:3783-3790. $\underline{\text { https://doi.org/10.1002/adma.200701709 }}$

[3] J Li, D Chen, G Chen (2005) Low-temperature thermal bonding of PMMA microfluidic chips. Anal. Lett 38:1127-1136. https://doi.org/10.1081/AL-200057209

[4] Ussing T, Petersen LV, Nielsen CB, Helbo B, Højslet L (2007) Micro laser welding of polymer microstructures 
using low power laser diodes. Int J Adv Manuf Tech 33:198-205. https://doi.org/10.1007/s00170-007-0969-0

[5] Huang FC, Chen YF, Lee GB (2007) CE chips fabricated by injection molding and polyethylene/thermoplastic elastomer film packaging methods. Electrophoresis 28:1130-1137. https://doi.org/10.1002/elps.200600351

[6] Sari F, Hoffmann WM, Haberstroh E, Poprawe R (2008) Applications of laser transmission processes for the joining of plastics, silicon and glass micro parts. Microsyst. Technol 14:1879-1886. https://doi.org/10.1007/s00542-008-0675-3

[7] Sackmann J, Burlage K, Gerhardy C, Memering B, Liao S, Schomburg WK (2015) Review on ultrasonic fabrication of polymer micro devices. Ultrasonics 56:189-200. https://doi.org/10.1016/j.ultras.2014.08.007

[8] Wu WQ, Peng HJ, Jia YL, Jiang BY (2017) Characteristics and mechanisms of polymer interfacial friction heating in ultrasonic plasticization for micro injection molding. Microsyst. Technol 23:1385-1392. https://doi.org/10.1007/s00542-016-2877-4

[9] Zhang ZB, Wang XD, Luo Y, Zhang ZQ, Wang LD (2010) Study on Heating Process of Ultrasonic Welding for Thermoplastics. J Thermoplast Compos 23:647-664. https://doi.org/10.1177/0892705709356493

[10] Matheny MP, Graff KF (2015) Ultrasonic welding of metals. In: Gallego-Juárez JA and Graffpp KF (ed) Power Ultrasonics, 1st edn. Woodhead Publishing, England, pp 259-293

[11] Benatar A (2015) Ultrasonic welding of plastics and polymeric composites. In: Gallego-Juárez JA and Graffpp KF (ed) Power Ultrasonics, 1st edn. Woodhead Publishing, England, pp 295-312

[12] Truckenmueller R, Chen Y, Ahrens R, et al (2006) Micro ultrasonic welding: Joining of chemically inert polymer microparts for single material fluidic components and systems. Microsyst. Technol 12:1027-1029. https://doi.org/10.1007/s00542-006-0136-9

[13] Li JM, Meng FJ, Liang C, Liu C (2017) Energy director structure and self-balancing jig for the ultrasonic bonding of microfluidic chips. Micro Nano Lett 12:453-457. https://doi.org/10.1049/mnl.2017.0028

[14] Kim JB, Jeong BW, Chiao M, Lin LW (2009) Ultrasonic bonding for MEMS sealing and packaging. IEEE T Adv Packaging 32:461-467. https://doi.org/10.1109/TADVP.2008.2009927

[15] Zhang ZB, He QQ, Yan CQ (2014) Non-Melt Ultrasonic Bonding Method for Polymer MEMS Devices. AMM 607:133-138. https://doi.org/10.4028/www.scientific.net/AMM.607.133

[16] Sun YB, Teng TD, Guo GQ, Wu GX (2019) An ultrasonic bonding method controlled by the characteristic waveform of ultrasonic propagation. Micro Nano Lett 14:547-550.https://.doi.org/10.1049/MNL.2018.5461 
Figures

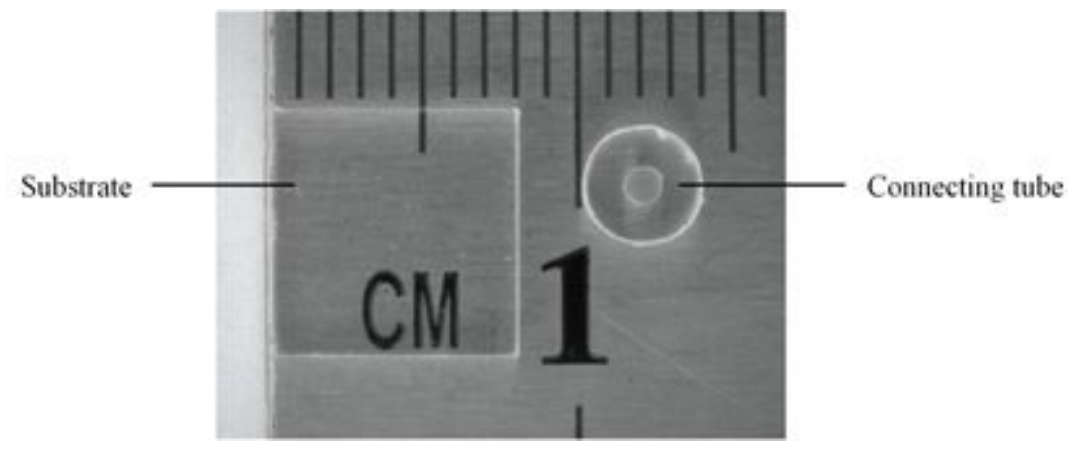

\section{Figure 1}

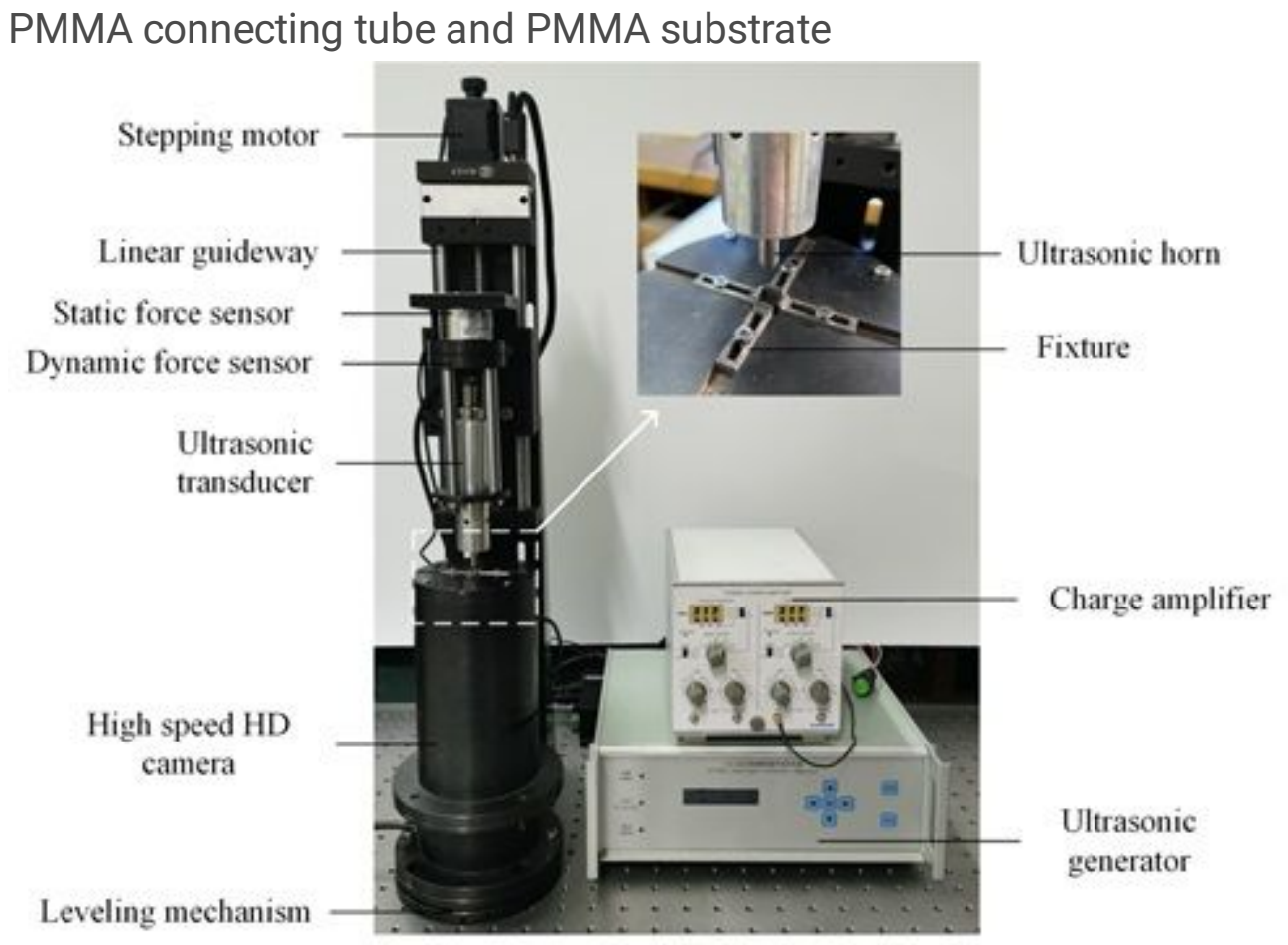

Figure 2

The ultrasonic precise bonding test rig 


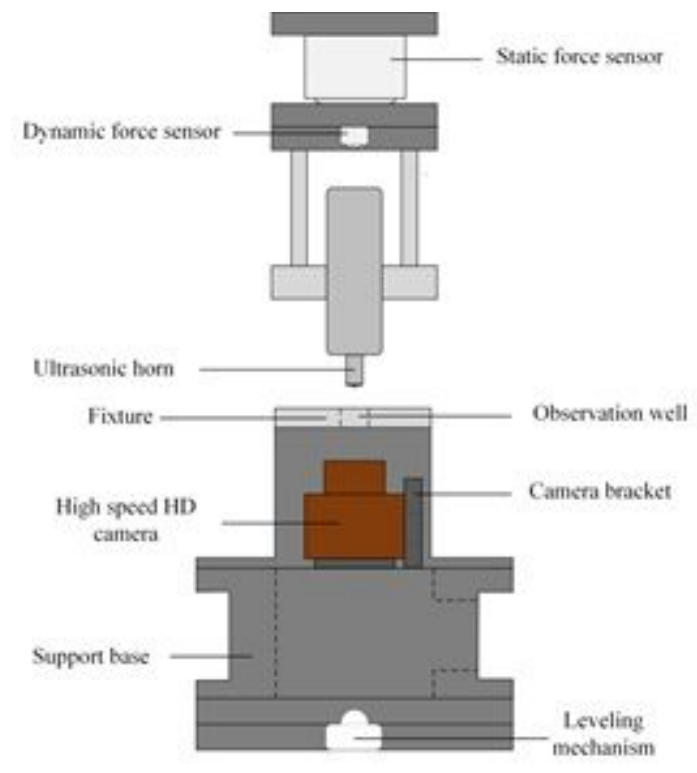

Figure 3

The basic principle diagram of the polymer ultrasonic precise bonding test rig

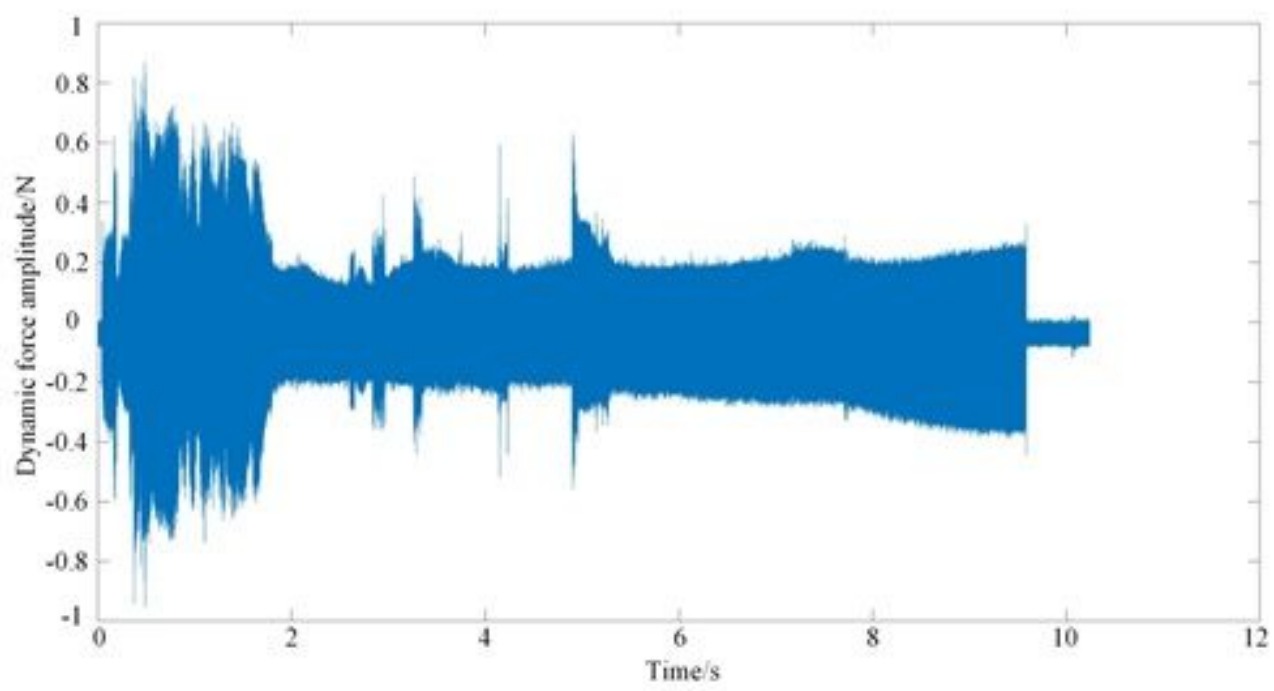

Figure 4

The time-domain waveform of the ultrasonic guided wave 


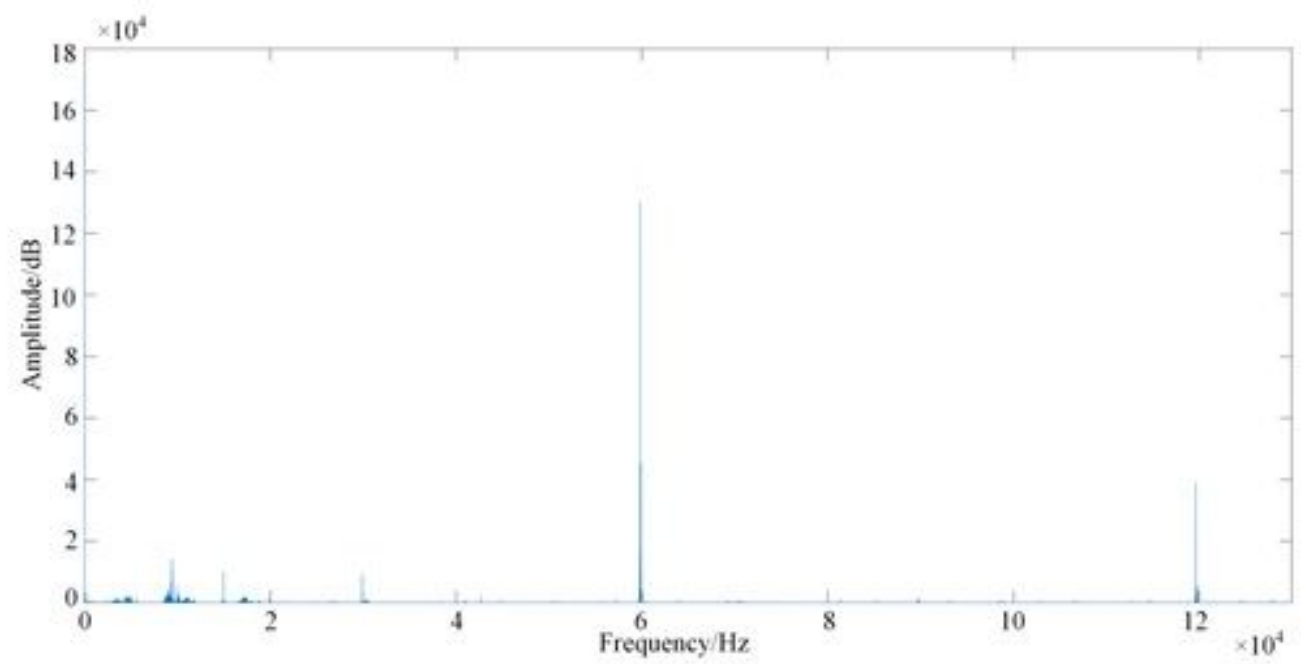

\section{Figure 5}

The spectrum of the ultrasonic guided wave

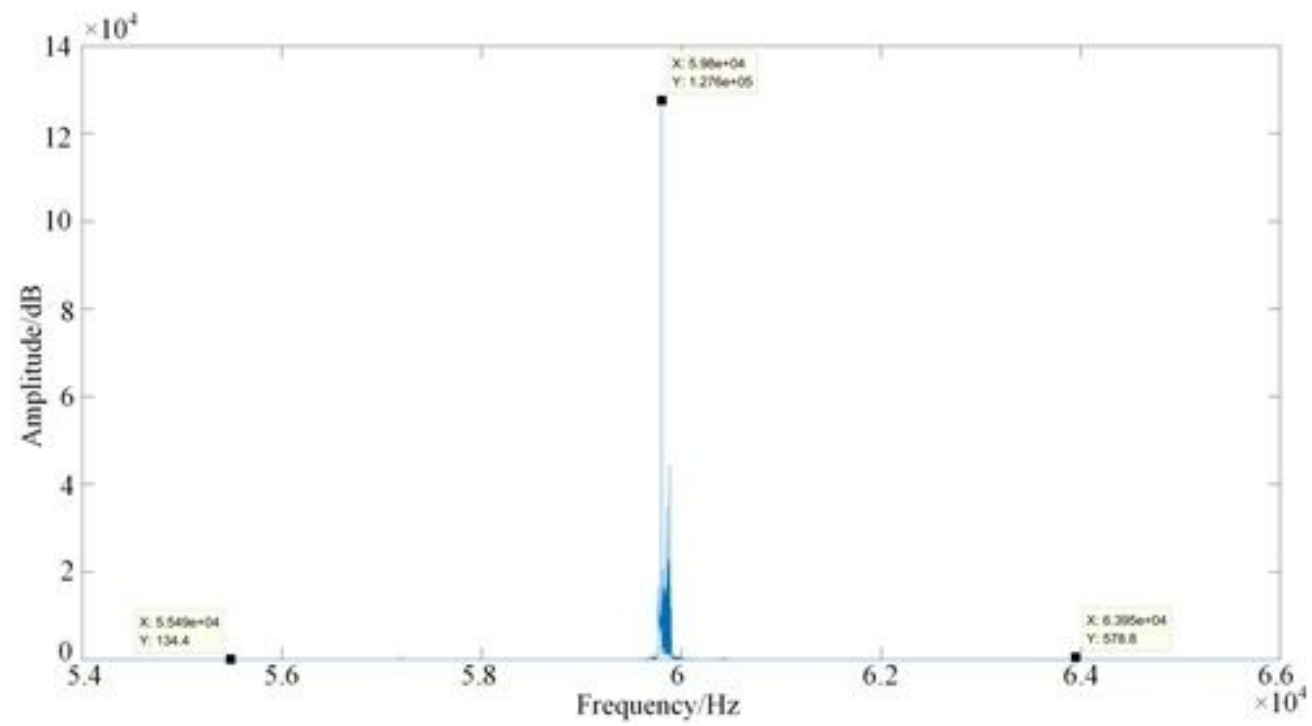

Figure 6

The frequency spectrum of the $60 \mathrm{kHz}$ main frequency band 


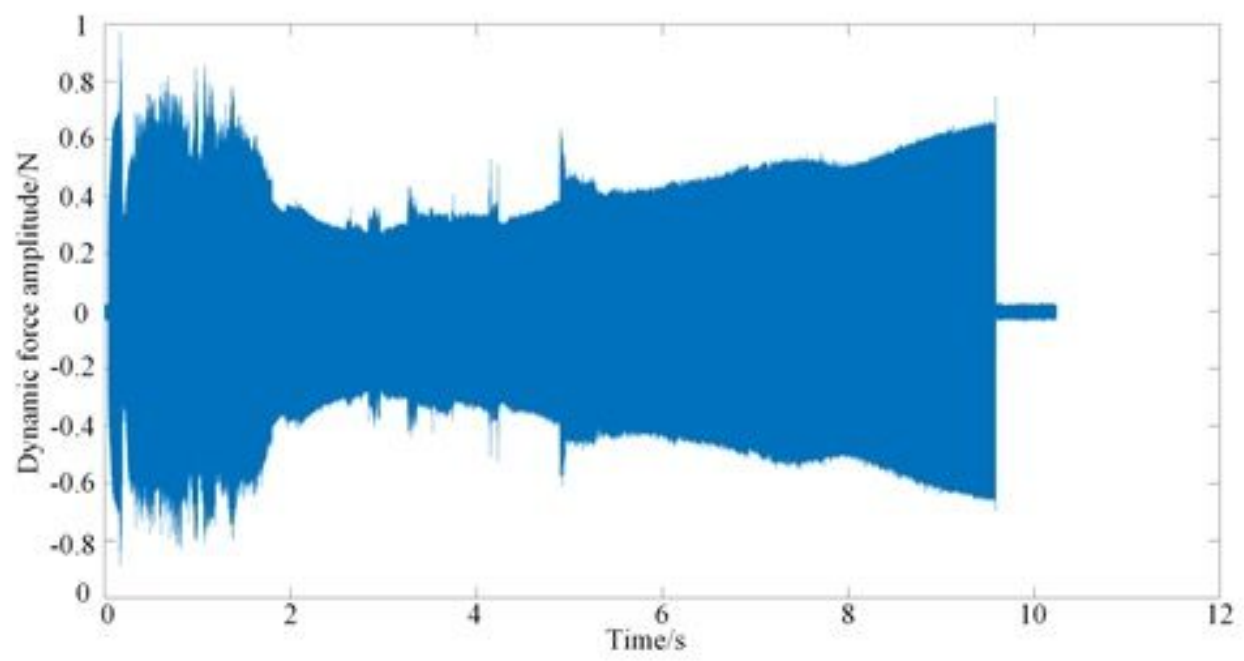

Figure 7

The characteristic waveform of [31.250 62.500]kHz frequency band

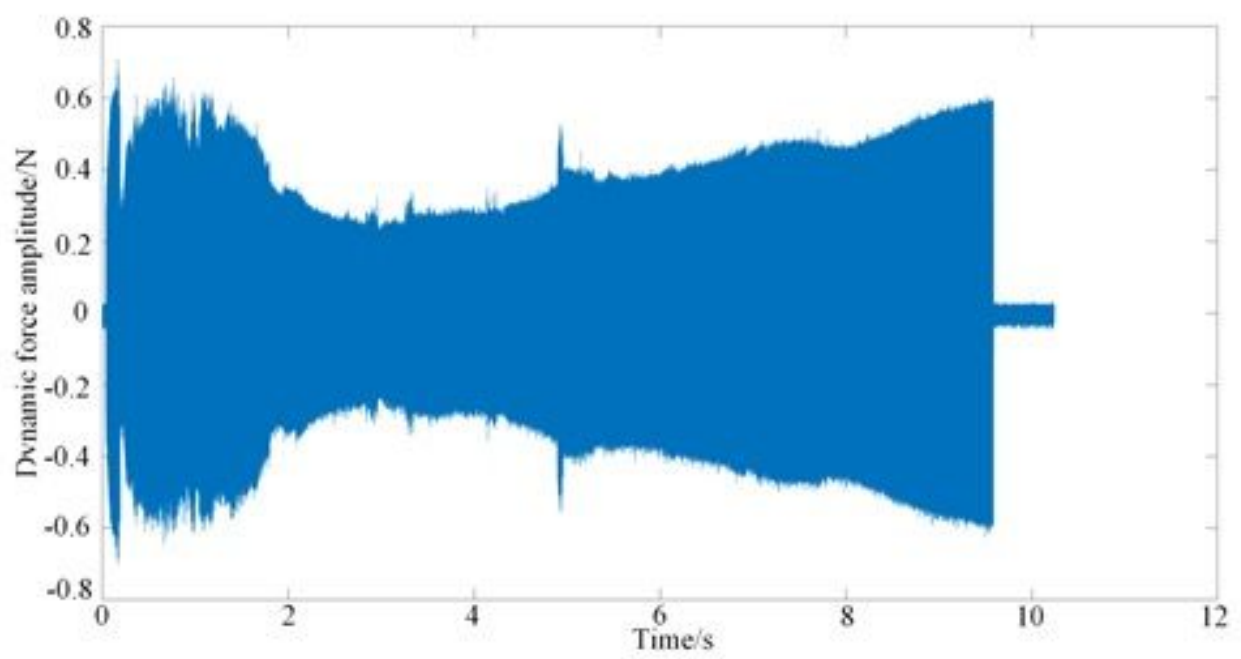

Figure 8

The characteristic waveform of [62.500 93.750]kHz frequency band 


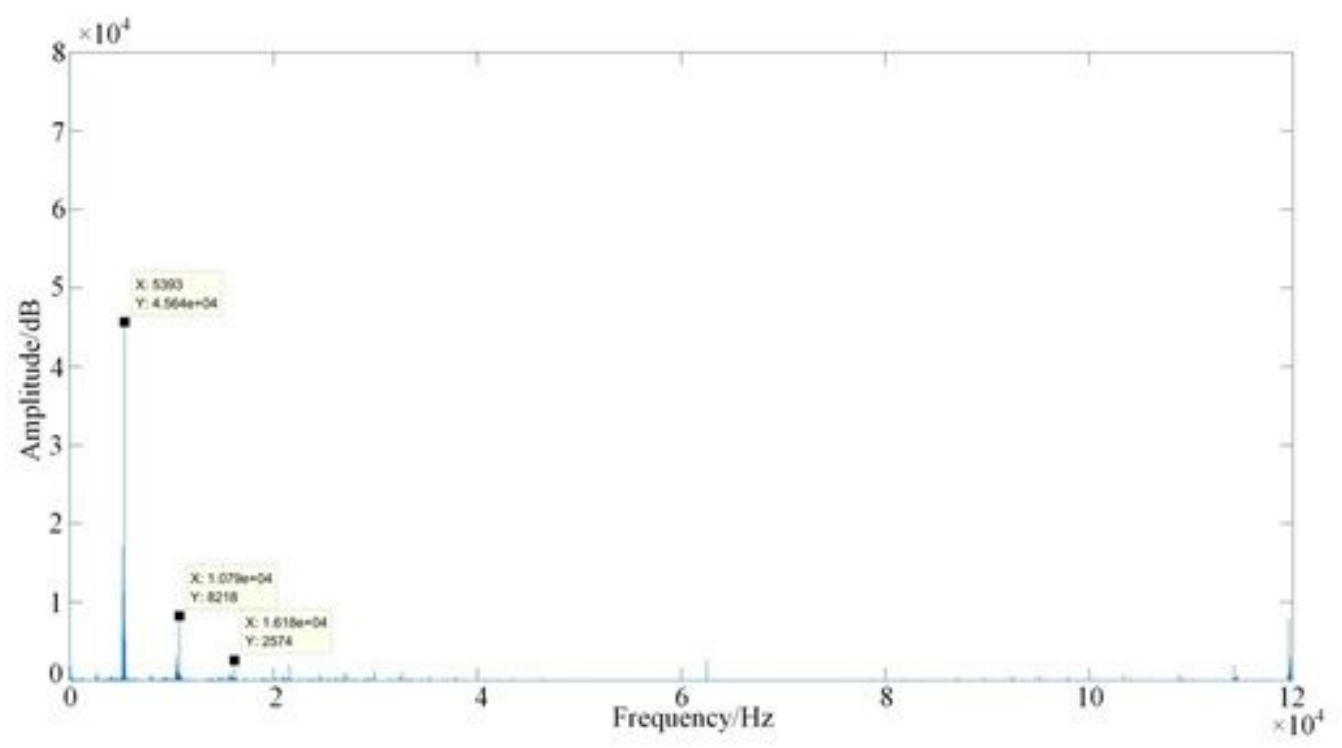

\section{Figure 9}

The envelope spectrum of the characteristic waveform in the $60 \mathrm{kHz}$ main frequency band

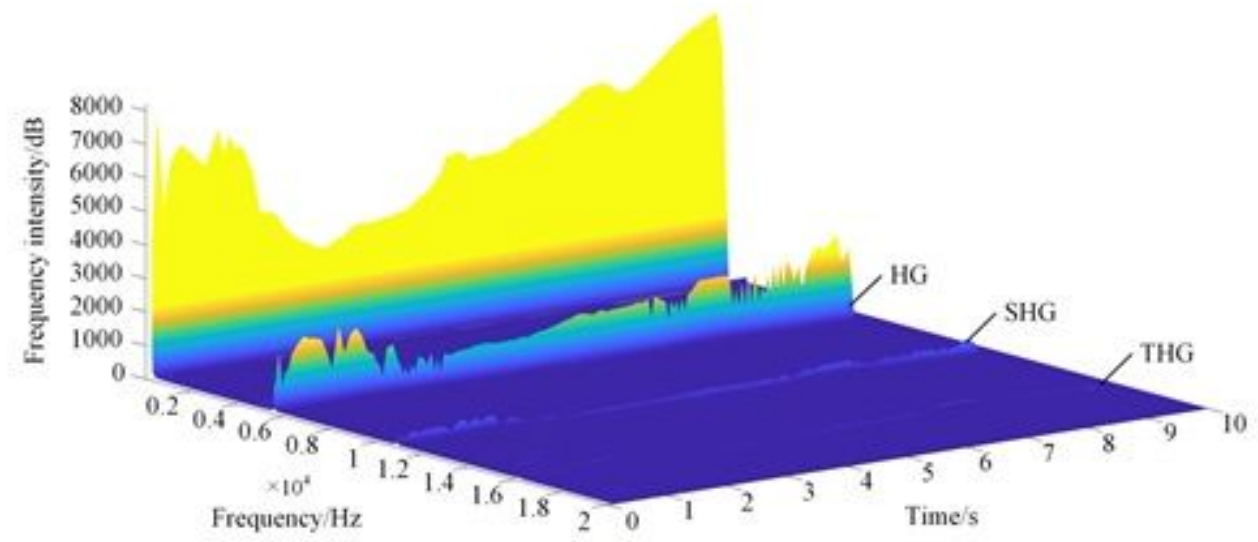

Figure 10

The three-dimensional diagram of the HG, SHG, and THG time-frequency characteristics 


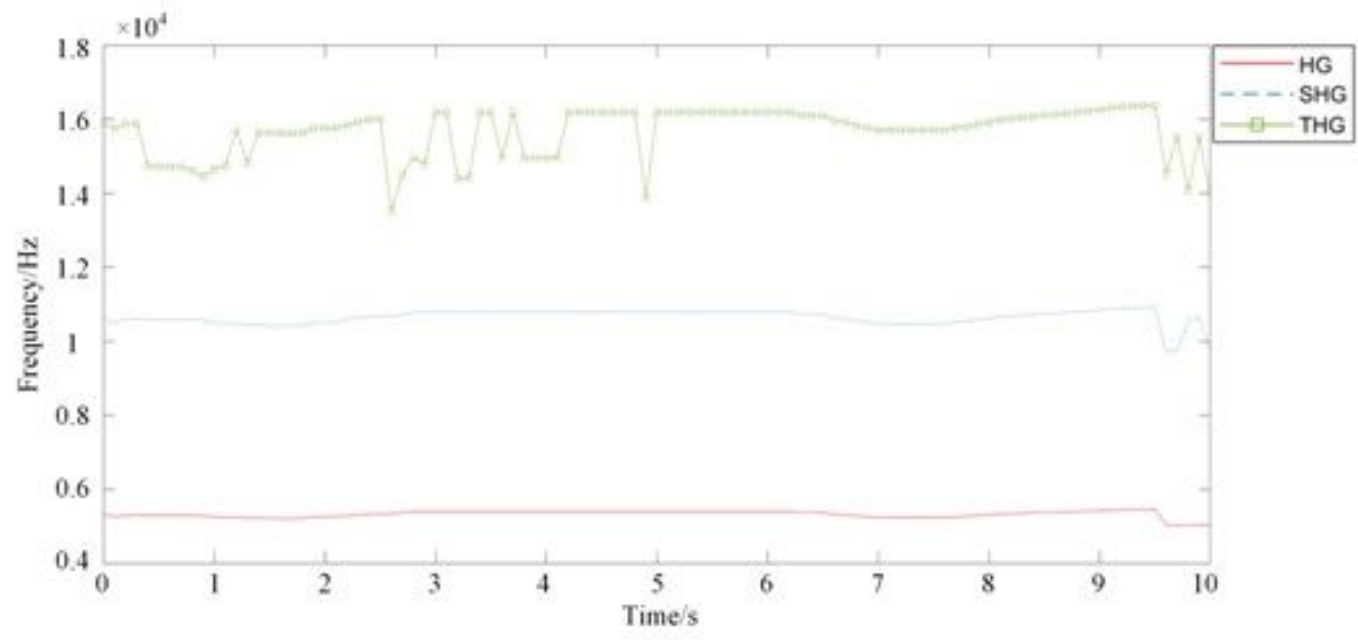

\section{Figure 11}

The time-harmonic frequency characteristics diagram

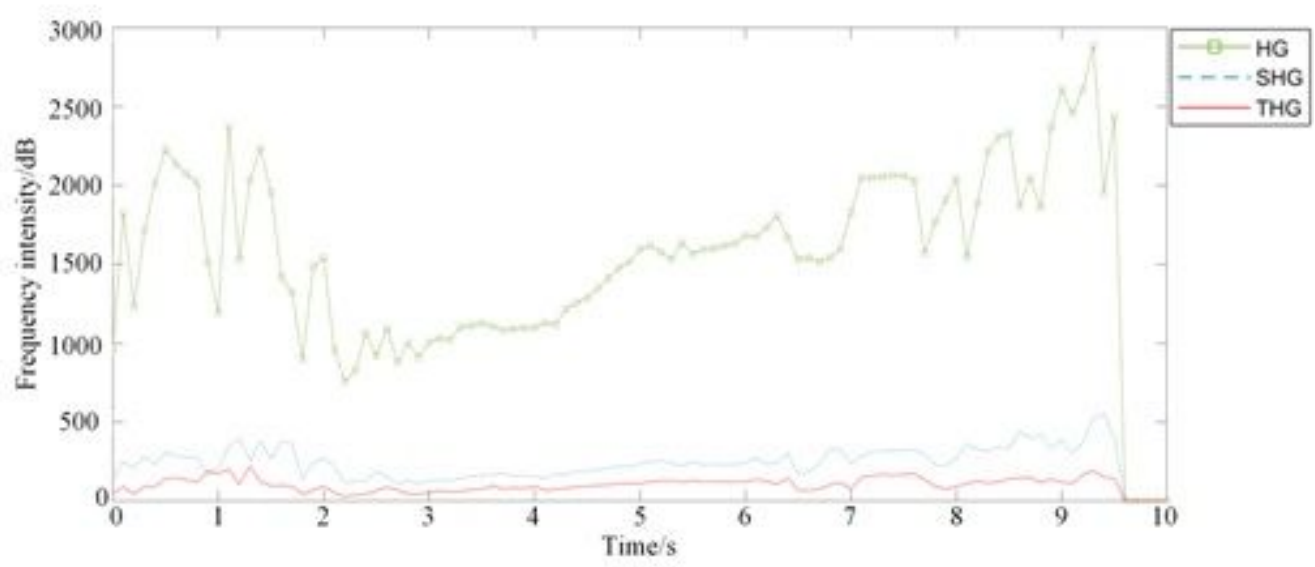

Figure 12

The time-harmonic frequency intensity characteristics diagram 


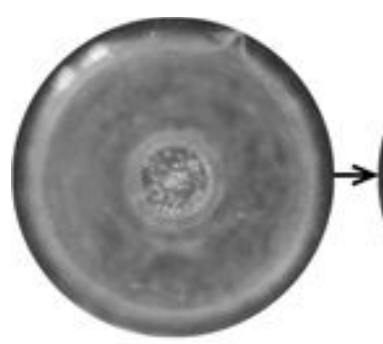

Start

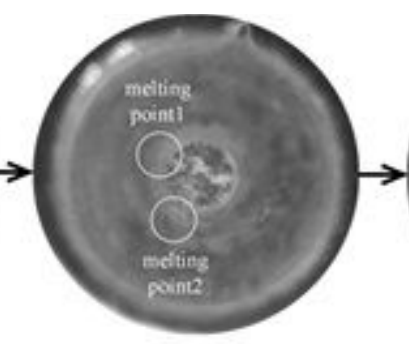

Characteristics point I

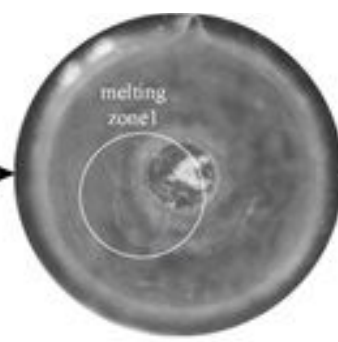

Characteristics point 2

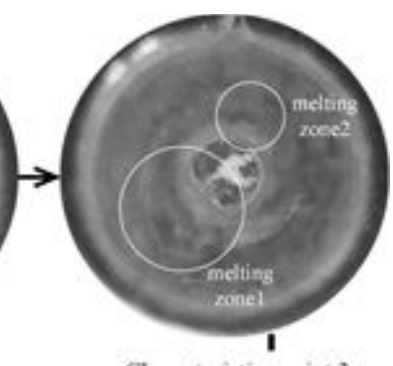

Characteristics point 3

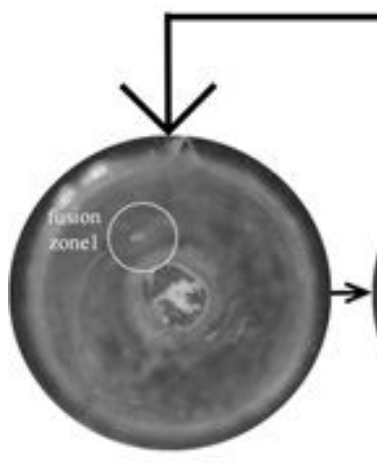

Characteristics point 4

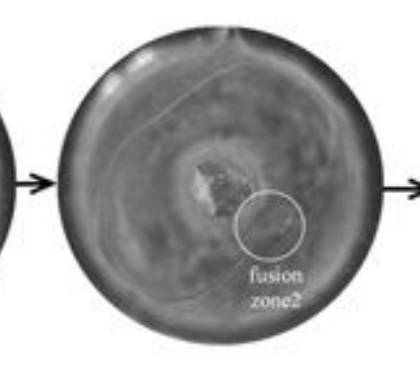

Characteristics point 5

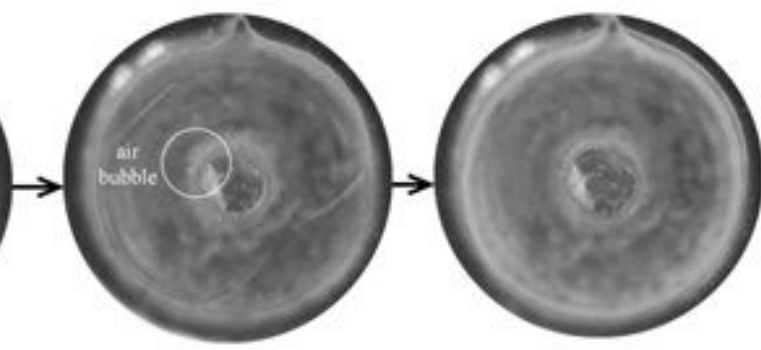

Characteristics point 6

\section{Figure 13}

The thermal melt interface of the micro-device

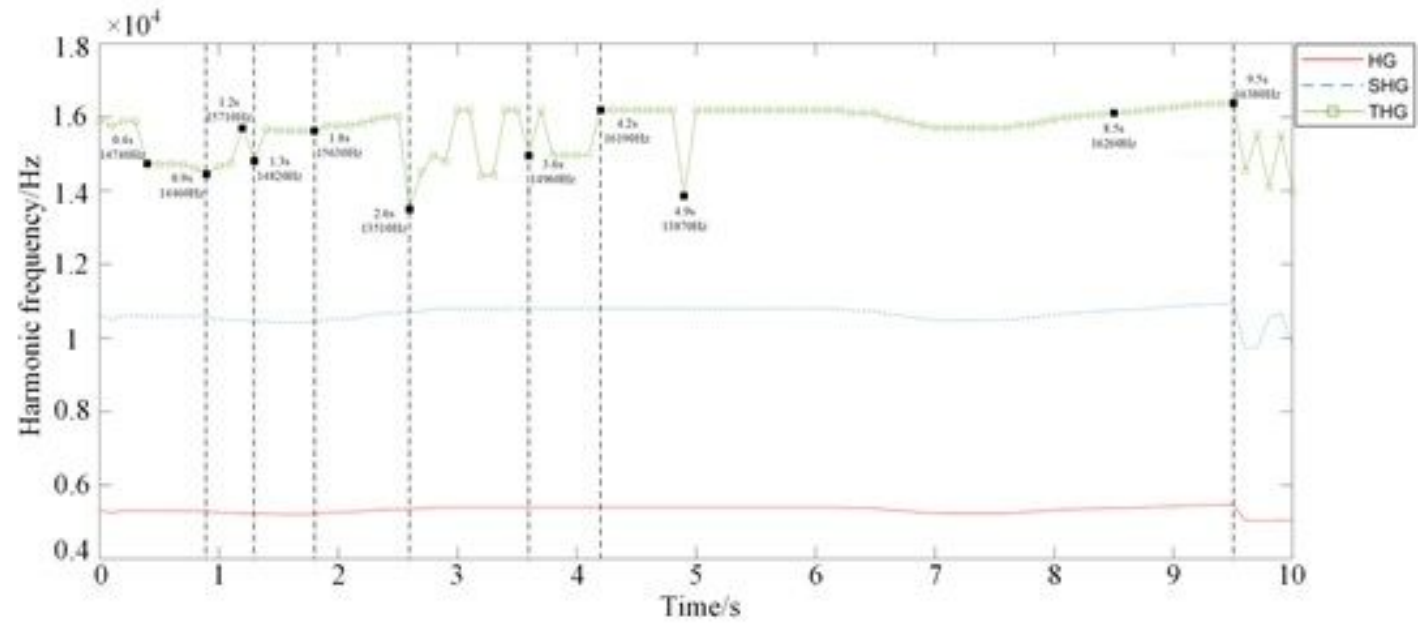

Figure 14

The correlation of thermal melt state and time-harmonic frequency 


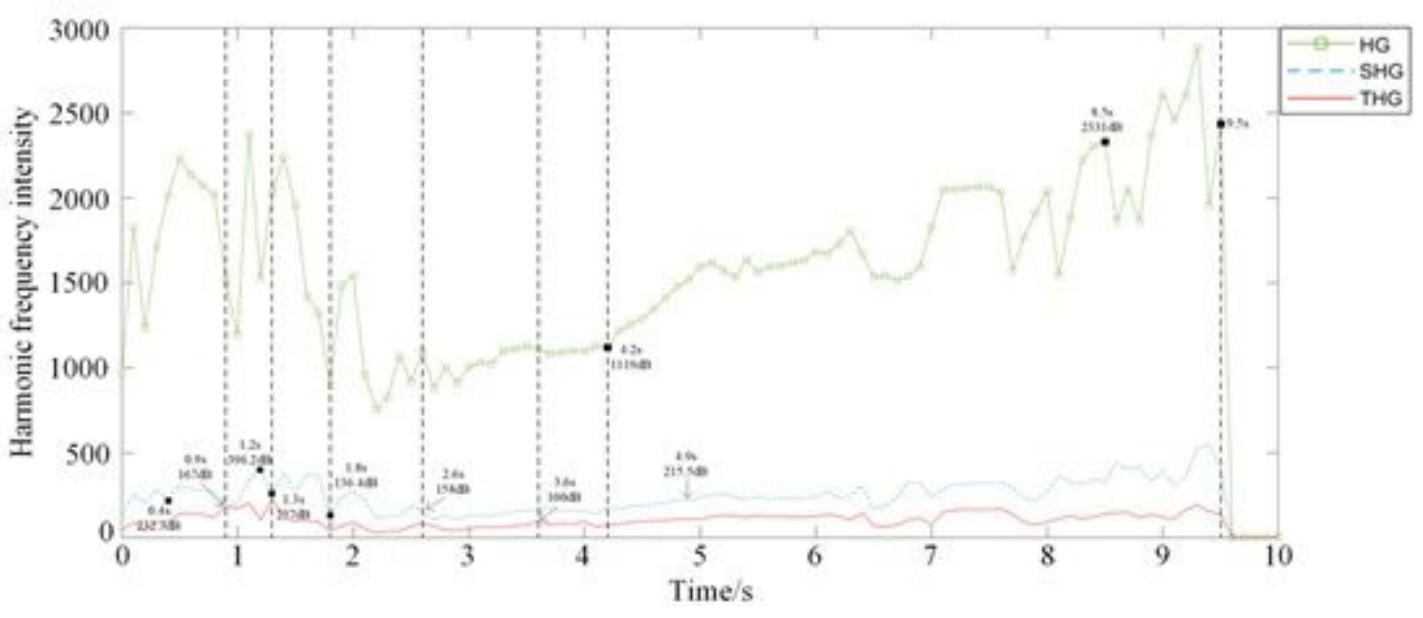

Figure 15

The correlation of thermal melt state and time-harmonic frequency intensity
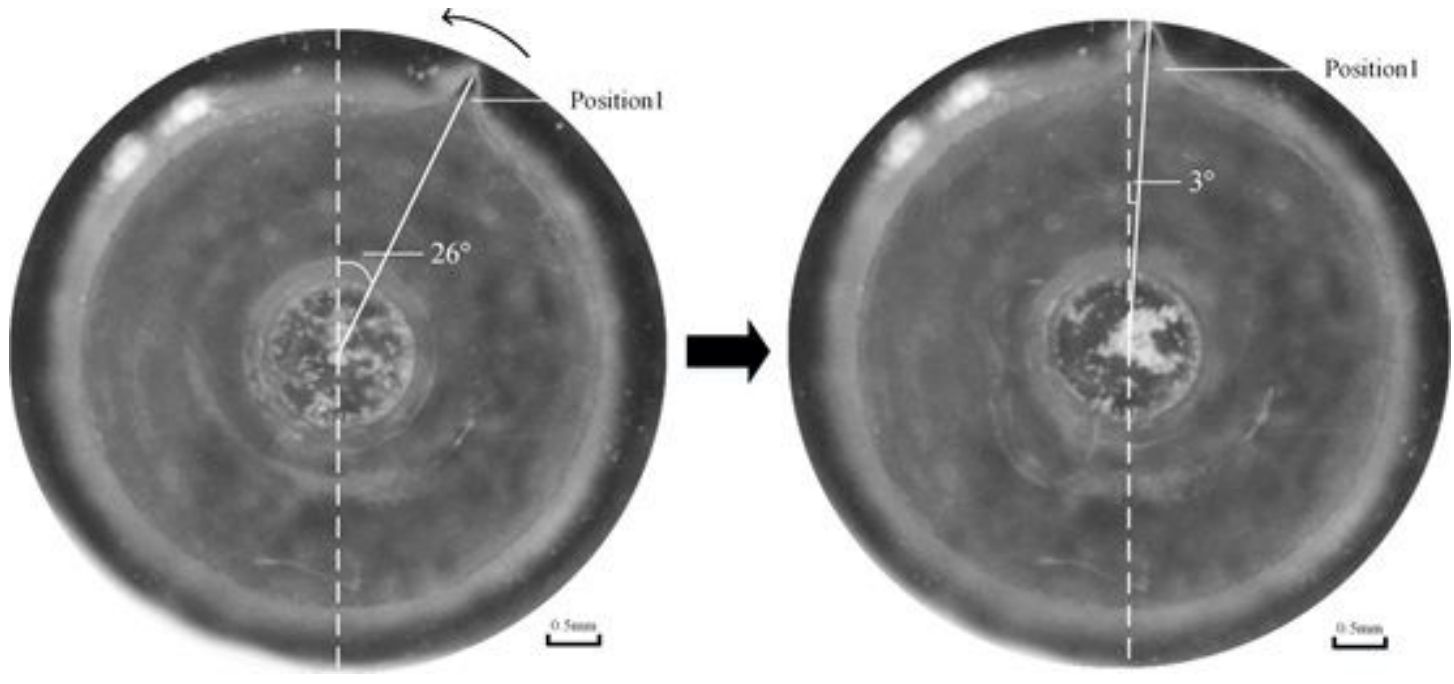

Figure 16

The rotation process of the micro-device

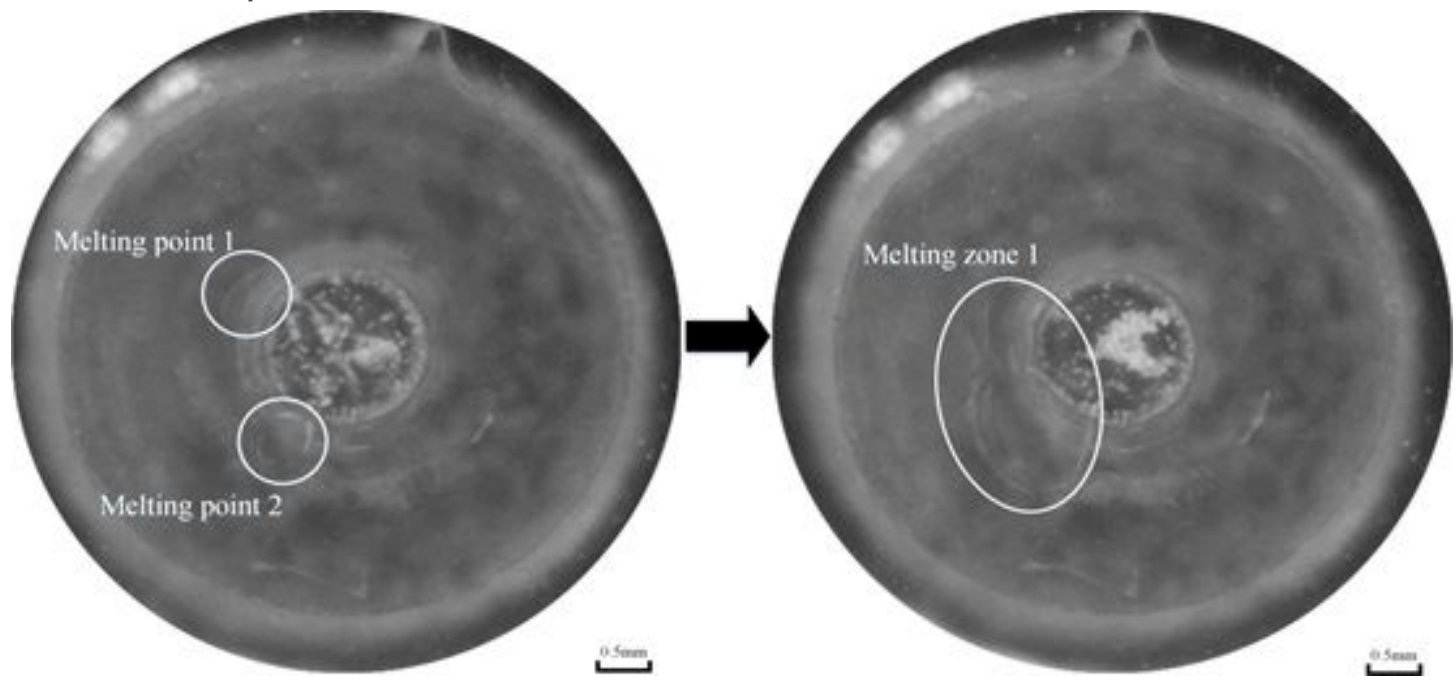


Figure 17

The fusion process of melting zone 1
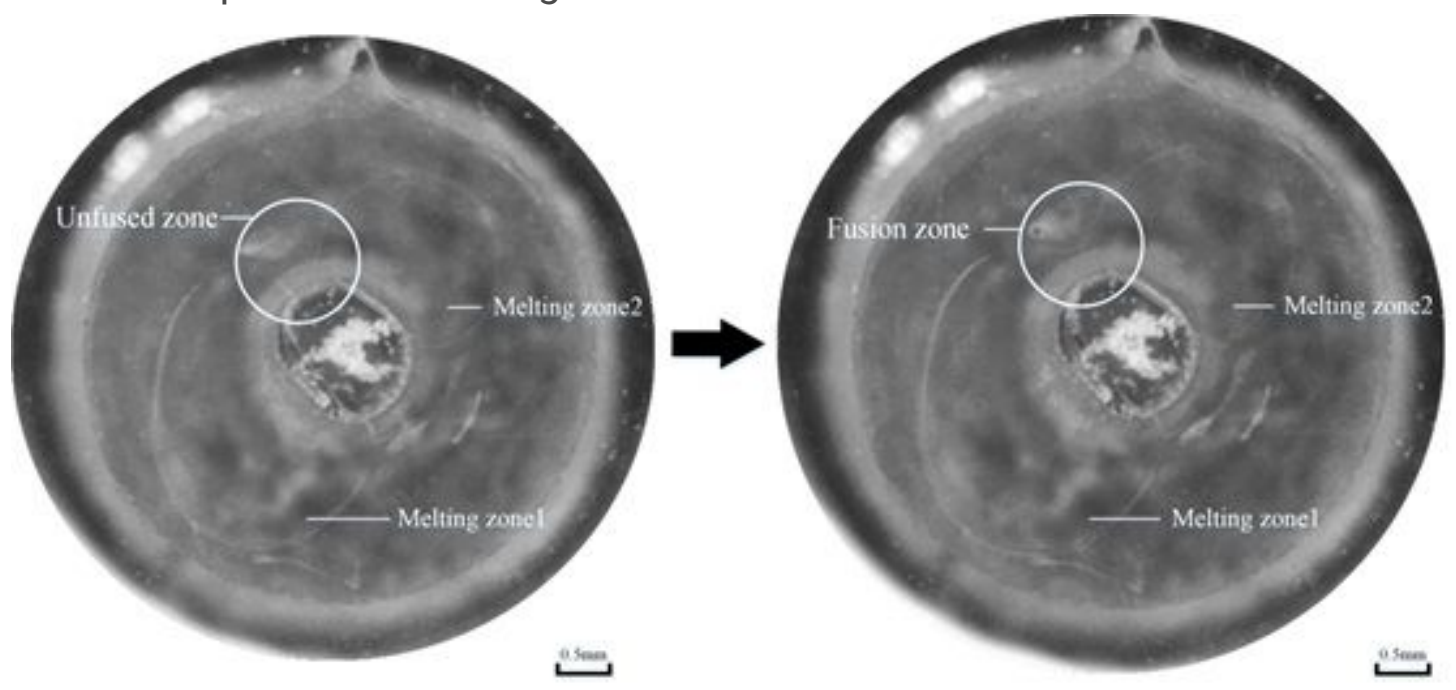

Figure 18

The local fusion process of melting zones 1 and 2
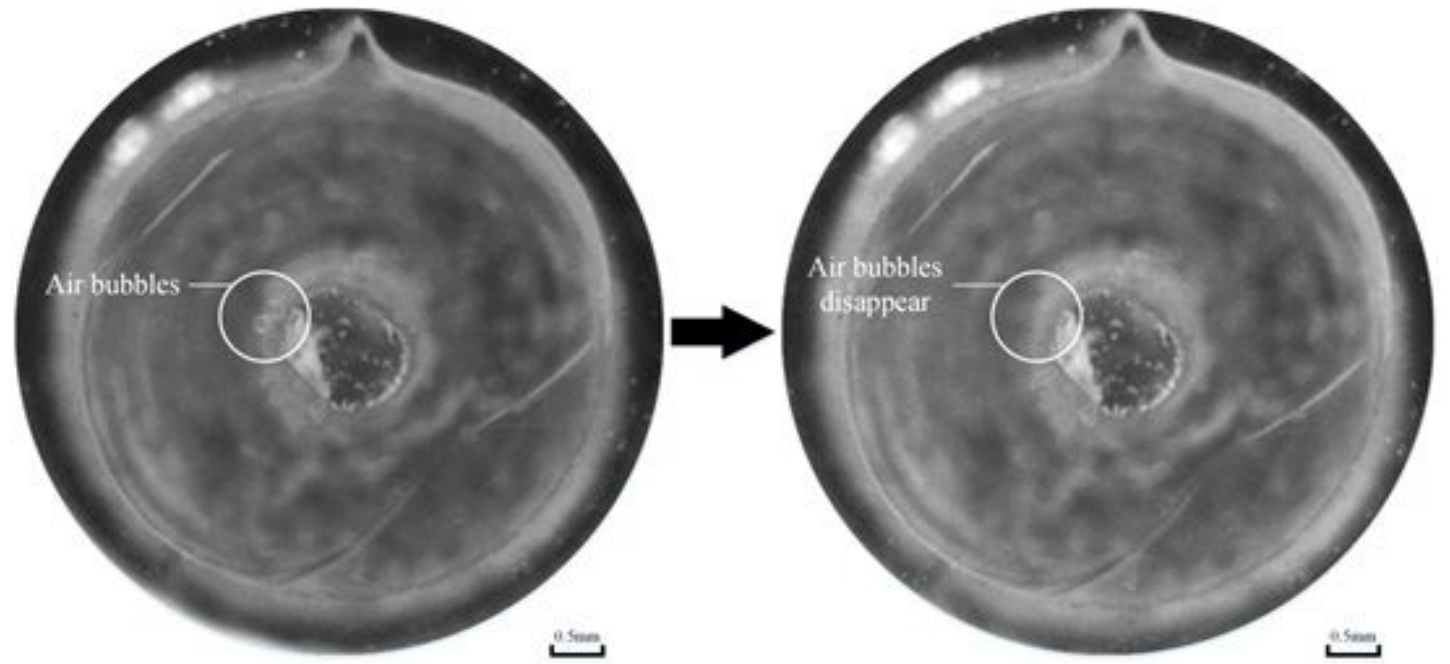

Figure 19

The disappearance process of local air bubbles on the thermal melt interface 